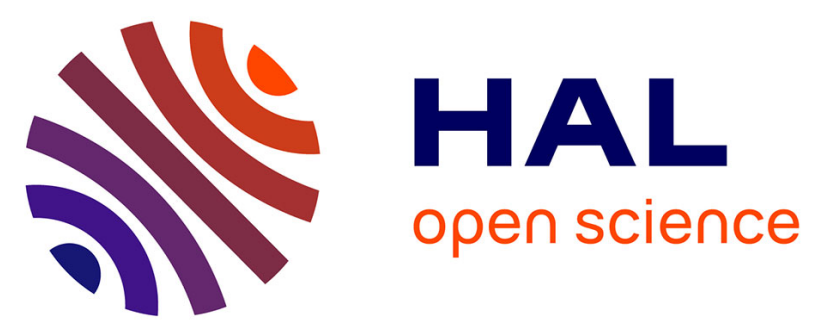

\title{
Near-Infrared Phosphorescent Hybrid Organic-Inorganic Perovskite with High-Contrast Dielectric and Third-Order Nonlinear Optical Switching Functionalities
}

\author{
Miroslaw Maczka, Andrzej Nowok, Jan Zaręba, Dagmara Stefańska, Anna
}

Gagor, Monika Trzebiatowska, Adam Sieradzki

\section{To cite this version:}

Miroslaw Maczka, Andrzej Nowok, Jan Zaręba, Dagmara Stefańska, Anna Gagor, et al.. Near-Infrared Phosphorescent Hybrid Organic-Inorganic Perovskite with High-Contrast Dielectric and Third-Order Nonlinear Optical Switching Functionalities. ACS Applied Materials \& Interfaces, 2022, 14 (1), pp.1460-1471. 10.1021/acsami.1c20557 . hal-03525378

\section{HAL Id: hal-03525378 \\ https://hal.science/hal-03525378}

Submitted on 13 Jan 2022

HAL is a multi-disciplinary open access archive for the deposit and dissemination of scientific research documents, whether they are published or not. The documents may come from teaching and research institutions in France or abroad, or from public or private research centers.
L'archive ouverte pluridisciplinaire HAL, est destinée au dépôt et à la diffusion de documents scientifiques de niveau recherche, publiés ou non, émanant des établissements d'enseignement et de recherche français ou étrangers, des laboratoires publics ou privés. 


\title{
Near-Infrared Phosphorescent Hybrid Organic-Inorganic Perovskite with High-Contrast Dielectric and Third-Order Nonlinear Optical Switching Functionalities
}

\author{
Mirosław Mączka,* Andrzej Nowok, Jan K. Zaręba,* Dagmara Stefańska, Anna Gągor, \\ Monika Trzebiatowska, and Adam Sieradzki
}

Cite This: ACS Appl. Mater. Interfaces 2022, 14, 1460-1471

Read Online

ABSTRACT: Hybrid organic-inorganic perovskites providing integrated functionalities for multimodal switching applications are widely sought-after materials for optoelectronics. Here, we embark on a study of a novel pyrrolidinium-based cyanide perovskite of formula $\left(\mathrm{C}_{4} \mathrm{H}_{10} \mathrm{~N}\right)_{2} \mathrm{KCr}(\mathrm{CN})_{6}$, which displays thermally driven bimodal switching characteristics associated with an order-disorder phase transition. Dielectric switching combines two features important from an application standpoint: high permittivity contrast $\left(\Delta \varepsilon^{\prime}=38.5\right)$ and very low dielectric losses. Third-order nonlinear optical switching takes advantage of third-harmonic generation (THG)

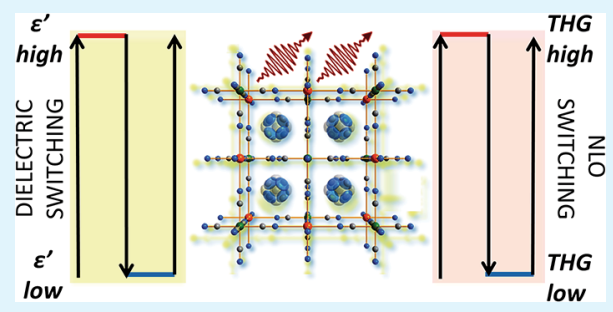
bistability, thus far unprecedented for perovskites and coordination polymers.

Structurally, $\left(\mathrm{C}_{4} \mathrm{H}_{10} \mathrm{~N}\right)_{2} \mathrm{KCr}(\mathrm{CN})_{6}$ stands out as the first example of a three-dimensional stable perovskite among formate-, azide-, and cyanide-based metal-organic frameworks comprising large pyrrolidinium cations. Its stability, reflected also in robust switching characteristics, has been tracked down to the $\mathrm{Cr}^{3+}$ component, the ionic radius of which provides a large enough metal-cyanide cage for the pyrrolidinium cargo. While the presence of polar pyrrolidinium cations leads to excellent switchable dielectric properties, the presence of $\mathrm{Cr}^{3+}$ is also responsible for efficient phosphorescence, which is remarkably shifted to the near-infrared region ( 770 to 880 $\mathrm{nm}$ ). The presence of $\mathrm{Cr}^{3+}$ was also found indispensable to the THG switching functionality. It is also found that a closely related cobalt-based analogue doped with $\mathrm{Cr}^{3+}$ ions displays distinct near-infrared phosphorescence as well. Thus, doping with $\mathrm{Cr}^{3+}$ ions is an effective strategy to introduce phosphorescence as an additional functional property into the family of cobalt-cyanide thermally switchable dielectrics.

KEYWORDS: chromium, phosphorescence, dielectric switching, nonlinear optics, coordination polymers, third-harmonic generation switching

\section{INTRODUCTION}

Hybrid organic-inorganic perovskites (HOIPs) have generated tremendous attention due to their unique physicochemical properties, which can be tailored by prudent choice of organic and inorganic components. ${ }^{1-5}$ Much publicity has grown particularly around those materials that exhibit coexistence of two or more functional properties in one phase; hence, multiple functionalities can be harnessed to perform more than one task at the same time. ${ }^{6-8}$ Furthermore, coupling between different physicochemical properties may lead to emergent phenomena, thus enabling construction of new types of multifunctional devices. ${ }^{9,10}$ Prime examples of such multifunctionality in the broad perovskite family are three-dimensional (3D) lead halides exhibiting optoelectronic, photovoltaic, and nonlinear optical (NLO) properties. ${ }^{2,3,5,11}$ Multifunctionality, however, is not confined only to classic lead halide HOIPs; indeed, multifunctional properties were also reported for a number of $3 \mathrm{D}$ perovskites composed of metal centers linked by multiatomic ligands such as $\mathrm{HCOO}^{-}$, $\mathrm{H}_{2} \mathrm{POO}^{-}$, or $\mathrm{N}(\mathrm{CN})_{2}{ }^{-}$. For instance, some formates were shown to exhibit multiferroic properties, ${ }^{12,13}$ hypophosphites demonstrate coexistence of magnetic properties and photoluminescence (PL), ${ }^{14,15}$ and dicyanamides feature concomitant $\mathrm{PL}$ and second-order nonlinear optical (NLO) properties. ${ }^{16,17}$

One of the most widely investigated functionalities of $3 \mathrm{D}$ HOIPs is PL because this property is attractive for various applications, including LEDs, lasers, lighting, remote thermometers, etc. ${ }^{10,15,18}$ In lead perovskites, PL originates from recombination of excitons, ${ }^{4,10}$ but PL in HOIPs may also originate from transitions between electronic levels of metal centers $^{8,15}$ or organic compounds. ${ }^{4}$ In the case of metal centers, $\mathrm{Cr}^{3+}$ is one of the most important PL species. ${ }^{19-22} \mathrm{PL}$ associated with this transition metal cation depends strongly

Received: October 25, 2021

Accepted: December 20, 2021

Published: December 30, 2021 
on the crystal field strength and changes from a broad band in the near-IR (NIR) region for the weak crystal field $\left({ }^{4} \mathrm{~T}_{2 \mathrm{~g}} \rightarrow{ }^{4} \mathrm{~A}_{2 \mathrm{~g}}\right.$ fluorescence) to narrow in the red region (usually near 700 $\mathrm{nm})$ for the $\mathrm{Cr}^{3+}$ in the strong crystal field $\left({ }^{2} \mathrm{E}_{\mathrm{g}} \rightarrow{ }^{4} \mathrm{~A}_{2 \mathrm{~g}}\right.$ phosphorescence). ${ }^{19,20,23}$ The phosphorescence of a ruby was utilized for construction of a solid-state red laser. ${ }^{24}$ Recently, there is growing interest in finding materials exhibiting efficient emission in the NIR region because such radiation has good penetration of organic matter and finds application in bioimaging, sensors, photovoltaics, optical communications, etc. ${ }^{21,22,25,26}$ Materials comprising $\mathrm{Cr}^{3+}$ are good candidates for NIR sources since they can be easily excited with the available blue LEDs. ${ }^{21}$ NIR fluorescence has been reported mainly for oxide inorganic materials, ${ }^{19,21,22}$ whereas NIR phosphorescence has been observed for some compounds comprising $\mathrm{Cr}^{3+}$ coordinated to nitrogen atoms ${ }^{20,25,26}$ or carbon atoms of cyanide ions. $^{27,28}$ It is important to add that rational design of NIR phosphorescent materials with improved PL quantum yield requires maximizing the ligand field strength since a large energy gap between the ${ }^{2} \mathrm{E}_{\mathrm{g}}$ and ${ }^{4} \mathrm{~T}_{2 \mathrm{~g}}$ states minimizes back intersystem crossing. ${ }^{20}$

Peculiar subtypes of multifunctional materials constitute switchable HOIPs, i.e., those whose physicochemical responses can be turned on (high) and off (low) by means of external stimuli such as temperature or pressure. By far, the most frequently targeted switching-based functionalities are dielectric switching and NLO switching. The former feature in HOIPs is highly relevant for modern technologies, i.e., sensors, switches, memory devices, signal processing, etc. ${ }^{29,30}$ It is typically achieved by the change of the mobility of polar ions between the static (low dielectric) and dynamic (high dielectric) states. Accordingly, significant dielectric anomalies require the presence of polar species, usually protonated amines, as well as necessitate their reversible ordering/ disordering at a certain temperature or pressure. A coordination net that hosts organic cations plays a role but less obvious than organic guests. Regardless of their chemical identity, candidates for dielectric switching should be chemically stable and resistant to fatigue upon multiple switching cycles, and the dielectric response to an external stimulus should be fast. ${ }^{31}$ Weak frequency dependence of the dielectric permittivity is also a much coveted property.

Thus far, switchable dielectric properties were reported mainly for metal halides, ${ }^{3,7,29,32-34}$ but compounds with other linkers, for instance, perchlorate or thiocyanate, are also known. $^{30,34}$ Most of the discovered compounds present isolated metal-ligand clusters, not beneficial for optical properties. $^{35} 3 \mathrm{D}$ perovskite-type switchable dielectrics are still scarce and include methylhydrazinium lead bromide, ${ }^{3}$ dimethylammonium cadmium azide, ${ }^{36,37}$ and tetrapropylammonium cadmium dicynamide. ${ }^{38}$ However, the dielectric anomalies in these $3 \mathrm{D}$ perovskites are very weak and/or strongly frequency-dependent. ${ }^{3,36-38}$ In that context, the most promising family of $3 \mathrm{D}$ switchable perovskites constitutes cyanides of the general formula $\mathrm{A}_{2} \mathrm{M}^{\mathrm{I}} \mathrm{M}^{\mathrm{III}}(\mathrm{CN})_{6}(\mathrm{~A}=$ organic cation; $\mathrm{M}^{\mathrm{I}}=\mathrm{Na}, \mathrm{K}$, or $\mathrm{Rb} ; \mathrm{M}^{\mathrm{III}}=\mathrm{Co}, \mathrm{Fe}$, or $\mathrm{Cr}$ ). A step-like change of dielectric permittivity was reported for a few cobalt $^{39-45}$ and iron ${ }^{42,43,46,47}$ cyanides, but a reversible change between on and off states by a thermal stimulus was demonstrated only for cobalt analogues comprising methylammonium $\left(\mathrm{MA}^{+}\right)$and iron analogues comprising $\mathrm{MA}^{+}$and dimethylammonium $\left(\mathrm{DMA}^{+}\right)$cations. ${ }^{39,47}$ It is worth noting that we have discovered switchable properties controlled by temperature also for a nonperovskite cobalt cyanide network comprising pyrrolidinium $\left(\mathrm{Pyr}^{+}\right)$cations. ${ }^{48}$ Furthermore, we demonstrated for the first time that the change between on and off states in this compound may also be achieved by applying external pressure. ${ }^{49}$ Regarding chromium perovskite analogues, step-like dielectric anomalies were reported for two analogues only, i.e., $\mathrm{DMA}_{2} \mathrm{KCr}(\mathrm{CN})_{6}$ and $\mathrm{MA}_{2} \mathrm{KCr}(\mathrm{CN})_{6} \cdot{ }^{39,50}$ In the latter case, the switching between on and off states was demonstrated but suffered from a poor stability of its $\varepsilon^{\prime}$ upon prolonged cycling due to decomposition. ${ }^{39}$ The above inputs served as guideposts, stimulating our research in the direction of chromium cyanide-based perovskite materials that feature high-contrast dielectric switching but with much improved stability.

Switching of NLO properties in hybrid materials has become another leading theme these days. Although nonlinear optics offers a wide palette of second- and higher-order NLO phenomena that could be employed for that purpose, SHG is an absolutely dominant pathway by which the switching of NLO response is realized. Specifically, SHG switching is a second-order NLO outcome of temperature-induced transitions between crystal phases in which at least one of them is noncentrosymmetric. ${ }^{34,51-59}$ However, we see a great deal of untapped potential in the analogue parametric NLO process, namely, the third-harmonic generation (THG). By contrast to SHG, THG occurs in crystalline solids of any symmetry; hence, THG switching can be, in principle, performed even for all-centrosymmetric solids. Indeed, despite that fact, temperature-driven THG switching has never been reported for HOIPs, to the extent of our knowledge. What is even more perplexing, there were no attempts to employ THG for simple monitoring of structural phase transitions in HOIPs as well. Accordingly, the use of THG for perovskite material discovery is generally an uncharted territory that needs exploration.

The following contribution is devoted to the chromium cyanide network $\operatorname{Pyr}_{2} \mathrm{KCr}(\mathrm{CN})_{6}$, which was found to feature two disparate kinds of switching phenomena: dielectric switching and THG switching. While dielectric switching itself is not a new matter, the major advancement that we present is that we have overcome stability challenges of chromium cyanide networks by employing pyrrolidinium cations as an organic guest. By doing this, we have also managed to enhance the main merits of this dielectric switch, i.e., a very high contrast of the dielectric response $\left(\Delta \varepsilon^{\prime}=38.5\right)$ and fast switching (minimum switching time $=1 \mathrm{~min}$ ). We place a particular emphasis on the importance of the latter parameter, which is often overlooked but being of utmost importance for real-life applications.

We also demonstrate for the first time the THG switching for HOIP material, taking $\mathrm{Pyr}_{2} \mathrm{KCr}(\mathrm{CN})_{6}$ as a model. While this particular aspect of the present paper is much more of exploratory than applicational character, for the very first time, we provide proof of concept of efficient THG switching between two crystalline phases in HOIP material. By going beyond the former path of SHG to more exotic NLO phenomena, we paved the way to the development of alternative but still useful NLO switching schemes. Since the title compound is thus far an unknown material featuring phase transition behavior, characterization with X-ray crystallography, vibrational (IR and Raman) spectroscopies, and thermal techniques has been performed as well. Furthermore, we also targeted unusual phosphorescence properties of the title compound, adding up to its multifunctional character. It is 
worth noting that in order to better understand the relationship between the structure and optical properties of the cyanides comprising $\mathrm{Pyr}^{+}$cations, we also report an optical study of the previously discovered nonperovskite cobalt analogue $\mathrm{Pyr}_{2} \mathrm{KCo}(\mathrm{CN})_{6}$ doped with $\mathrm{Cr}^{3+}$ ions.

\section{EXPERIMENTAL SECTION}

Synthesis. In order to grow $\mathrm{Pyr}_{2} \mathrm{KCr}(\mathrm{CN})_{6}$ crystals, $2.6 \mathrm{~mL}$ of pyrrolidine $(30 \mathrm{mmol})$ dissolved in $20 \mathrm{~mL}$ of water was neutralized with about $3 \mathrm{~mL}$ of hydrochloric acid. Then, $5 \mathrm{mmol}$ of $\mathrm{K}_{3} \mathrm{Cr}(\mathrm{CN})_{6}$ was dissolved in this solution on a hot plate at $50{ }^{\circ} \mathrm{C}$ under stirring for $2 \mathrm{~h}$, the heating was switched off, and the solution was left at RT. After one week, yellow crystals were separated from the mother liquid and dried. The same method was used to grow $\mathrm{Pyr}_{2} \mathrm{KCo}(\mathrm{CN})_{6}: \mathrm{Cr}^{3+}$ crystals, but the mixture contained respective amounts of $\mathrm{K}_{3} \mathrm{Cr}(\mathrm{CN})_{6}$ and $\mathrm{K}_{3} \mathrm{Co}(\mathrm{CN})_{6}$. The comparison of their powder XRD patterns with the calculated ones based on the single-crystal data confirmed the phase purity of powdered samples (Figure S1 in the SI).

X-ray Powder Diffraction. Powder XRD patterns were measured in the reflection mode on an X'Pert PRO X-ray diffraction system equipped with a PIXcel ultrafast line detector and Soller slits for $\mathrm{Cu}$ $\mathrm{K} \alpha \alpha_{1}$ radiation $(\lambda=1.54056 \AA)$.

Differential Scanning Calorimetry (DSC). The heat flow was measured using a Mettler Toledo DSC-1 calorimeter with a high resolution of $0.4 \mu \mathrm{W}$. Nitrogen was used as a purging gas, and the sample weight was $22.50 \mathrm{mg}$. The calorimetric measurements were performed on heating and cooling cycles at rates of $1,2,5,10$, and 20 $\mathrm{K} \mathrm{min}^{-1}$. The excess heat capacity associated with the phase transition was evaluated by subtracting from the data the baseline representing the variation in the absence of the phase transitions.

Thermogravimetric Analysis (TGA). A TGA study was performed in the temperature range of $300-1130 \mathrm{~K}$ using a PerkinElmer TGA 4000. The sample weight was ca. $11.8 \mathrm{mg}$, and the heating speed rate was $10 \mathrm{~K} / \mathrm{min}$. Pure nitrogen gas as the atmosphere was used.

Single-Crystal X-ray Diffraction. The single-crystal X-ray diffraction data were collected at 295 and $100 \mathrm{~K}$ on an Xcalibur single-crystal diffractometer operating with graphite monochromated Mo $\mathrm{K} \alpha$ radiation $(\lambda=0.71073 \AA)$ and a CCD Atlas camera. CrysAlisPro was used for data processing (Rigaku Oxford Diffraction, 2015). Absorption correction was applied by using multiscan methods in the SCALE3 ABSPACK algorithm. The room temperature (RT) structure was solved by direct methods and refined using the fullmatrix least-squares method in the SHELXL2014/7 package. ${ }^{60}$ Owing to the disorder of $\mathrm{Pyr}^{+}$cations, the hydrogen atoms were not introduced into the refinement. The low-symmetry structure was not solved due to the complex twinning. Figure S2 presents the reciprocal space reconstructions taken in the cubic and the low-symmetry phases. Crystal data, data collection, refinement results, and selected bond lengths are shown in Table S1.

Raman and IR Measurements. Temperature-dependent Raman spectra were measured using a Renishaw inVia Raman spectrometer equipped with a confocal DM 2500 Leica optical microscope and a thermoelectrically cooled CCD as a detector. Excitation was performed using an argon laser $\left(\lambda_{\text {exc }}=488 \mathrm{~nm}\right)$. Temperaturedependent IR spectra were measured on a $\mathrm{KBr}$ pellet using a standalone Nicolet iN10 microscope. The spectral resolution in the Raman and IR studies was $2 \mathrm{~cm}^{-1}$. The temperature of the samples was controlled using a Linkam THMS 600 heating/freezing stage.

Broadband Dielectric Spectroscopy (BDS). The dielectric measurements were performed every $1 \mathrm{~K}$ using a Novocontrol Alpha impedance analyzer. The temperature (with stability higher than 0.1 K) was controlled by a Novocontrol Quatro system, by using a nitrogen gas cryostat. The single crystal with a crystallographic orientation perpendicular to the (001) plane had dimensions of $1.7 \times$ $1.2 \times 0.7 \mathrm{~mm}^{3}$. The silver paste was deposited on the surface as an electrode. The AC voltage with an amplitude of $1 \mathrm{~V}$ and frequency in the range $0.1 \mathrm{~Hz}$ to $1 \mathrm{MHz}$ was applied across the sample. Each switching cycle was registered as time-dependent dielectric permittivity for $30 \mathrm{~min}$ at two constant temperatures. The temperature ramp between these temperatures was kept at $5 \mathrm{~K} \mathrm{~min}^{-1}$.

Absorption and Photoluminescence Studies. For measurements of the absorption spectra, a Varian Cary 5E UV-vis-NIR spectrophotometer was used. Temperature-dependent PL spectra were recorded with a PMA-12 Hamamatsu photonic multichannel analyzer equipped with a BT-CCD linear image sensor, and 266 and $405 \mathrm{~nm}$ laser diodes were used as the excitation sources. The temperature of the samples during emission measurements was controlled using a Linkam THMS 600 heating/freezing stage. A temperature of $77 \mathrm{~K}$ was obtained using liquid nitrogen cooling, whereas for the phosphorescence measurement at $5 \mathrm{~K}$, the sample was placed in an Oxford CF 1204 continuous-flow helium cryostat equipped with a temperature controller.

THG Studies. Nonlinear optical studies were performed using a laser system consisting of a Coherent Astrella Ti:Sapphire regenerative amplifier providing $800 \mathrm{~nm}$ pulses ( $75 \mathrm{fs}$ pulse duration, $1 \mathrm{kHz}$ repetition rate) driving a wavelength-tunable TOPAS Prime optical parametric amplifier (OPA). The output of the OPA was set to $1350 \mathrm{~nm}$. Prior to the measurements, the single crystals of $\mathrm{Pyr}_{2} \mathrm{KCr}(\mathrm{CN})_{6}$ were crushed with a spatula, fixed between microscope glass slides (forming tightly packed layers), sealed, and mounted to the sample holder. The laser beam was directed onto the sample at 45 degrees and was unfocused. Signal-collecting optics, mounted to the glass optical fiber, was placed perpendicularly to the plane of the sample (backscattering geometry), which was placed on a horizontally aligned holder. Scattered pumping radiation was suppressed with the use of a $750 \mathrm{~nm}$ shortpass dielectric filter (FESH0750, Thorlabs). A temperature-resolved THG study was performed using a $1350 \mathrm{~nm}$ laser beam, with the power limited to 290 $\mathrm{mW}$ and a spot area of $0.5 \mathrm{~cm}^{2}$. This experiment was performed for four heating/cooling rates $\left(2,5,10\right.$, and $\left.20 \mathrm{~K} \mathrm{~min}^{-1}\right)$. The THG switching experiment was performed for three heating/cooling rates $\left(2,5\right.$, and $\left.10 \mathrm{~K} \mathrm{~min}^{-1}\right)$, and the same laser beam parameters were employed as for the TR-THG study. Temperature control of the sample was performed using a Linkam LTS420 heating/freezing stage. Excitation geometry, signal collection optics, and the sample preparation protocol were the same as for the THG switching experiment. The emission spectra collected in both experiments were recorded by an Ocean Optics Flame T spectrograph.

\section{RESULTS AND DISCUSSION}

Single-Crystal X-ray Diffraction. Unexpectedly, $\mathrm{Pyr}_{2} \mathrm{KCr}(\mathrm{CN})_{6}$ crystallizes in the cubic $F m \overline{3} m$ double perovskite structure (phase I, Table S1), isomorphic to the HT phases of $\mathrm{A}_{2} \mathrm{KFe}(\mathrm{CN})_{6}$ frameworks that crystallize with small ammonium cations such as formamidinium $\left(\mathrm{FA}^{+}\right),{ }^{43} \mathrm{MA}^{+},{ }^{42}$ or trimethylammonium $\left(3 \mathrm{MA}^{+}\right){ }^{61}$ It comprises a three-dimensional metal-cyanide scaffold and $\mathrm{Pyr}^{+}$cations deployed in the structure cavities around the $\overline{4} 3 m$ centers. $\mathrm{Cr}^{3+}$ ions are connected with six $\mathrm{K}^{+}$neighbors by $\mathrm{CN}^{-}$linkers $\left(\mathrm{Cr}^{\mathrm{III}}-\mathrm{C} \equiv\right.$ $\mathrm{N}-\mathrm{K}$ ). Both metal positions are coordinated by ideal $\mathrm{CrC}_{6}$ and $\mathrm{KN}_{6}$ octahedra of $\mathrm{O}_{h}$ symmetry. The details of the crystal structure are presented in Figure 1. Due to the thermally activated rotations, the ammonium cations are disordered around the centers of cubic cages.

Owing to the ionic character of $\mathrm{K}-\mathrm{N}$ bonds, the $\left[\mathrm{KM}^{\mathrm{III}}(\mathrm{CN})_{6}\right]$ framework is prone to significant distortions resulting from the $\mathrm{N}-\mathrm{H} \cdots \mathrm{N}$ hydrogen-bond ( $\mathrm{HB}$ ) interactions between ammonium cations and the framework. Depending on the size and shape of ammonium cations as well as the number and positions of proton donor centers, various low-symmetry polymorphs are stabilized already at RT. Both MA- and 3MAbased $\mathrm{KFe}^{\mathrm{III}}(\mathrm{CN})_{6}$ cyanides feature monoclinic $\mathrm{C} 2 / c \mathrm{RT}$ symmetry, ${ }^{61}$ whereas the $\mathrm{FA}$ analogue crystallizes in the triclinic $P \overline{1}$ space group. ${ }^{43}$ In $\operatorname{Pyr}_{2} \mathrm{KCr}(\mathrm{CN})_{6}$, the phase transition to the lower-symmetry polymorph II appears around 


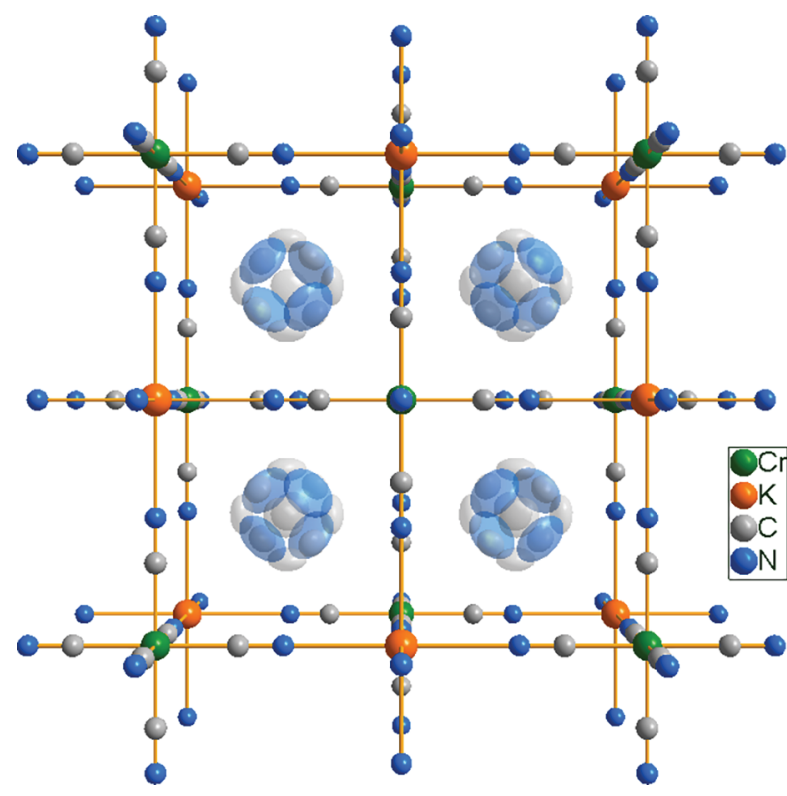

Figure 1. Crystal structure of $\operatorname{Pyr}_{2} \mathrm{KCr}(\mathrm{CN})_{6}$ in cubic phase I at 295 $\mathrm{K}$. $\mathrm{Pyr}^{+}$is massively disordered around the central point of the cage of $\overline{4} 3 m$ symmetry.

$235 \mathrm{~K}$. The diffraction patterns collected at $100 \mathrm{~K}$ unambiguously indicate the radical reduction of the crystal class, which is confirmed by a complex domain structure composed of at least 6 domain orientations. The ordering of $\mathrm{Pyr}^{+}$at relatively low temperatures compared to other small ammonium cations results most likely from the ability of this cation to easy conformational changes between twisted and envelope forms, which hinder freezing of cationic motions and hydrogen-bond interactions. ${ }^{62}$

It is well-known that structural tunability of perovskites is limited by the size of the cavities that organic cations can accommodate. In the case of formate, azide, and cyanide frameworks, the largest organic cation used to date for synthesis of stable perovskite was tetramethylammonium (ionic size of $292 \mathrm{pm}){ }^{63,64}$ For larger $\mathrm{Pyr}^{+}(320 \mathrm{pm})^{65}$ and thiazolium (ionic size of $320 \mathrm{pm}$ ), ${ }^{64} \mathrm{~A}_{2} \mathrm{KCo}(\mathrm{CN})_{6}$ analogues crystallize in nonperovskite structures containing large channels or cages. ${ }^{44,48}$ Thus, $\operatorname{Pyr}_{2} \mathrm{KCr}(\mathrm{CN})_{6}$ constitutes the first example of a stable perovskite in the family of formate-, azide-, and cyanide-metal frameworks comprising big $\mathrm{Pyr}^{+}$ cations. Inspection of crystallographic data for isostructural $\mathrm{DMA}_{2} \mathrm{KM}(\mathrm{CN})_{6}(\mathrm{M}=\mathrm{Co}, \mathrm{Fe}$, or $\mathrm{Cr})$ cyanides shows that the $\mathrm{M}-\mathrm{C}$ bonds (unit cell volume) increase from 1.894 and 1.924 $\AA\left(786.9 \AA^{3}\right)$ for the Co analogue ${ }^{40}$ to 1.932 and $1.944 \AA$ $\left(806.9 \AA^{3}\right)$ for the $\mathrm{Fe}$ analogue ${ }^{61}$ and 2.060 and $2.0805 \AA$ (840.3 $\AA$ ) for the $\mathrm{Cr}$ analogue ${ }^{50}$ due to the significantly larger ionic radius of $\mathrm{Cr}^{3+}(0.755 \AA)$ compared to $\mathrm{Fe}^{3+}(0.69 \AA)$ and $\mathrm{Co}^{3+}(0.685 \AA){ }^{66}$ This example shows that employment of $\mathrm{Cr}^{3+}$ allows formation of significantly larger perovskite cages compared to the $\mathrm{Co}$ and $\mathrm{Fe}$ analogues. As a result, whereas the $\mathrm{Pyr}^{+}$cation is too large to fit the perovskite cages in the $\mathrm{Pyr}_{2} \mathrm{KM}(\mathrm{CN})_{6}(\mathrm{M}=\mathrm{Co}$ or $\mathrm{Fe})$ frameworks, it fits in the perovskite cages of the chromium analogue. Therefore, our results show that the incorporation of $\mathrm{Cr}^{3+}$ cations could be an effective way to synthesize cyanide-based perovskites accommodating some organic cations larger than $300 \mathrm{pm}$, such as thiazolium, tropylium, or isopropylammonium.
Worth adding is that the stability of a perovskite structure is often predicted based on the parameter called the tolerance factor (TF). The concept of the TF was extended to HOIPs by Kieslich et al., ${ }^{67}$ and in the case of hybrid double perovskites $\mathrm{A}_{2} \mathrm{M}^{\mathrm{I}} \mathrm{M}^{\mathrm{III}} \mathrm{X}_{6}$, the $\mathrm{TF}$ can be calculated from the following equation:

$$
\sqrt{2}\left(r_{\mathrm{A}}+r_{\mathrm{X}}\right) /\left(r_{\mathrm{M}^{\mathrm{I}}}+r_{\mathrm{M}^{\mathrm{III}}}+h_{\mathrm{X}}\right)
$$

in which $r$ denotes the effective radii of $\mathrm{A}, \mathrm{X}, \mathrm{M}^{\mathrm{I}}$, or $\mathrm{M}^{\mathrm{III}}$ and $h_{\mathrm{X}}$ is the effective height of the anion. ${ }^{68}$ For simple perovskites, cubic phases are usually found for TFs in the range of 0.9-1.0, whereas for TFs in the range of $0.8-0.9$, perovskite networks are typically distorted, leading to lower-symmetry phases. ${ }^{65,67}$ For TFs higher than 1.0, the $3 \mathrm{D}$ perovskite structure becomes unstable, but there are some examples for $3 \mathrm{D}$ perovskites with TFs in the range of 1.0-1.1.,65,69 The calculated TFs are 1.071, 1.070, and 1.059 for $\operatorname{Pyr}_{2} \mathrm{KCo}(\mathrm{CN})_{6}, \operatorname{Pyr}_{2} \mathrm{KFe}(\mathrm{CN})_{6}$, and $\mathrm{Pyr}_{2} \mathrm{KCr}(\mathrm{CN})_{6}$, respectively. Although for all compounds, the TF is significantly larger than 1.0, the smaller value of the TF for the $\mathrm{Cr}$ analogue, when compared to the $\mathrm{Co}$ and $\mathrm{Fe}$ counterparts, is consistent with the higher stability of the $3 \mathrm{D}$ double perovskite structure for this compound. Another point worth commenting on is that the phase transition temperature from the cubic disordered phase is much lower for $\mathrm{Pyr}_{2} \mathrm{KCr}$ $(\mathrm{CN})_{6}(237.8 \mathrm{~K}$ on cooling) than for its MA analogue (447 K). ${ }^{39}$ A study of double perovskite cyanides comprising $\mathrm{MA}^{+}$ cations showed that the phase transition temperature decreases with an increasing TF, and the cubic phase would be stable below $298 \mathrm{~K}$ when the $\mathrm{TF}>0.873$. $^{68}$ Therefore, the large increase in the phase transition temperature when going from $\mathrm{Pyr}_{2} \mathrm{KCr}(\mathrm{CN})_{6}$ to $\mathrm{MA}_{2} \mathrm{KCr}(\mathrm{CN})_{6}$ can be attributed to the large decrease in the TF for the latter compound (the TF of $\mathrm{MA}_{2} \mathrm{KCr}(\mathrm{CN})_{6}$ is 0.825$){ }^{68}$ In the family of $\mathrm{Pyr}_{2} \mathrm{M}^{\mathrm{I}} \mathrm{Cr}(\mathrm{CN})_{6}$ compounds, the decrease in the TF (increase in the phase transition temperature) could be realized by replacing smaller $\mathrm{K}^{+}$cations with larger $\mathrm{Rb}^{+}$or $\mathrm{Cs}^{+}$cations.

Raman and IR. Since our attempts to solve the lowtemperature (LT) structure of $\mathrm{Pyr}_{2} \mathrm{KCr}(\mathrm{CN})_{6}$ were unsuccessful, we employed Raman and IR spectroscopic methods to obtain insight into the mechanism of the phase transition. Vibrational modes of $\operatorname{Pyr}_{2} \mathrm{KCr}(\mathrm{CN})_{6}$ can be subdivided into internal vibrations of $\mathrm{Pyr}^{+}$cations and $\mathrm{Cr}(\mathrm{CN})_{6}$ units, translations of $\mathrm{K}^{+}$and $\mathrm{Cr}(\mathrm{CN})_{6}$, and librations of $\mathrm{Cr}(\mathrm{CN})_{6}$. The RT phase (space group $F m \overline{3} m$ ) contains only one formula unit in the primitive cell. Since $\mathrm{Pyr}^{+}$cations are disordered, we can only calculate the number of vibrational modes for the metal-cyanide framework (Table S2). Inspection of Table S2 shows that translations of $\mathrm{K}^{+}$and $\mathrm{Cr}(\mathrm{CN})_{6}$ should contribute to two IR bands, whereas $\mathrm{Cr}(\mathrm{CN})_{6}$ librations ( $\mathrm{T}_{1 \mathrm{~g}}$ mode) should be silent. Factor group analysis also predicts that there should be four IR-active $\left(4 \mathrm{~T}_{1 \mathrm{u}}\right)$, six Raman-active $\left(2 \mathrm{~A}_{1 \mathrm{~g}}+2 \mathrm{E}_{\mathrm{g}}+2 \mathrm{~T}_{2 \mathrm{~g}}\right)$, and three silent $\left(\mathrm{T}_{1 \mathrm{~g}}+2 \mathrm{~T}_{2 \mathrm{u}}\right)$ internal modes of the $\mathrm{Cr}(\mathrm{CN})_{6}$ units. These modes can be classified as stretching and bending modes and described using the notation proposed by Jones ${ }^{70}$ (Table S2).

The most intense Raman and IR bands, observed at 2121 and $2116 \mathrm{~cm}^{-1}$, respectively (Table S3, Figure 3, and Figures $\mathrm{S} 3-\mathrm{S} 5)$, can be assigned to $\mathrm{CN}^{-}$stretching vibrations. ${ }^{48,71}$ Based on literature data reported for Prussian blue and related cyanides, we locate the remaining modes of the $\mathrm{Cr}(\mathrm{CN})_{6}$ units below $600 \mathrm{~cm}^{-1}$ (Table S3). ${ }^{71,72}$ The assignment of internal modes of $\mathrm{Pyr}^{+}$cations, proposed in Table S3, is based on 
Raman and IR data reported for nonperovskite $\mathrm{Pyr}_{2} \mathrm{KM}(\mathrm{CN})_{6}$ analogues $(\mathrm{M}=\mathrm{Co}$ or $\mathrm{Fe}) .^{48}$

When temperature decreases, Raman and IR spectra exhibit drastic changes near $230 \mathrm{~K}$, in line with the first-order character of the phase transition. First, the single $\nu \mathrm{CN}$ IR (Raman) band splits into a triplet at $2127+2122+2117 \mathrm{~cm}^{-1}$ $\left(2131+2126+2121 \mathrm{~cm}^{-1}\right)$ (Table S3, Figure 2, and Figures

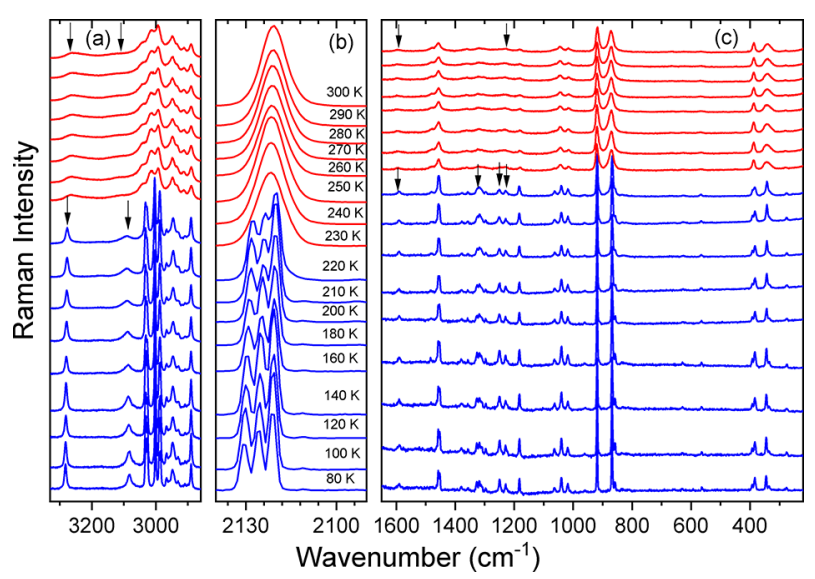

Figure 2. Temperature-dependent Raman spectra of $\mathrm{Pyr}_{2} \mathrm{KCr}(\mathrm{CN})_{6}$ in the (a) 3330-2860, (b) 2140-2090, and (c) $1650-220 \mathrm{~cm}^{-1}$ ranges. Arrows indicate modes related to vibrations of the $\mathrm{NH}_{2}$ group.

S3-S5). The fact that the Raman and IR modes are observed at different wavenumbers indicates that the LT phase is centrosymmetric. Furthermore, splitting of these bands into triplets is consistent with the complete lifting of degeneracy for the $\mathrm{T}_{1 \mathrm{u}}\left(\nu_{6}\right)$ IR-active mode and the $\mathrm{E}_{\mathrm{g}}\left(\nu_{3}\right)$ Raman-active mode. The lifting of degeneracy and the presence of the inversion center are consistent with lowering of the LT phase symmetry to orthorhombic (point group $D_{2 h}$ ), monoclinic (point group $C_{2 h}$ ), or triclinic (point group $C_{i}$ ). However, the fact that phase transition entropy is very large, comparable to those observed for FA and MA double perovskite cyanides exhibiting a phase transition to triclinic and monoclinic phases, respectively, suggests that symmetry of the LT phase is either monoclinic or triclinic. A decrease in the $\mathrm{Cr}(\mathrm{CN})_{6}$ site symmetry is further evidenced by splitting of the $\nu_{4}, \nu_{10}$, and $\nu_{11}$ Raman-active modes (Table S3). Note that in contrary to $\mathrm{FA}_{2} \mathrm{KCo}(\mathrm{CN})_{6}$ and $\mathrm{FA}_{2} \mathrm{KFe}(\mathrm{CN})_{6}$, which showed subtle changes of the $\mathrm{CN}$-related Raman and IR bands at the phase transitions, ${ }^{43}$ the corresponding changes are very pronounced for $\mathrm{Pyr}_{2} \mathrm{KCr}(\mathrm{CN})_{6}$. This behavior indicates that the phase transition leads to a much stronger distortion of the chromium cyanide framework in $\operatorname{Pyr}_{2} \mathrm{KCr}(\mathrm{CN})_{6}$ than the metal-cyanide frameworks in the FA analogues. Second, both Raman and IR bands exhibit significant narrowing. This behavior is prevalent for a majority of $\mathrm{Pyr}^{+}$bands, in particular the bands related to vibrations of the $\mathrm{NH}_{2}$ group (see Raman bands near 3260 and $3080 \mathrm{~cm}^{-1}$ in Figure 2 as well as IR bands near 3260, 3100, $1590,1400,1356,1320,1247,1220$, and $858-811 \mathrm{~cm}^{-1}$ in Figure S5). For instance, the full width at half maximum (FWHM) value of the Raman-active $\nu \mathrm{NH}_{2}$ mode at $3260 \mathrm{~cm}^{-1}$ ( $300 \mathrm{~K}$ value) changes from $66.9 \mathrm{~cm}^{-1}$ at $300 \mathrm{~K}$ to $7.3 \mathrm{~cm}^{-1}$ at $80 \mathrm{~K}$. This behavior proves that the highly disordered $\mathrm{Pyr}^{+}$ cations in the high-temperature (HT) phase become wellordered in the LT phase. Third, the $\mathrm{NH}_{2}$-related bands exhibit significant shifts. For instance, the IR-active $\nu \mathrm{NH}_{2}$ modes shift from 3261 and $3117 \mathrm{~cm}^{-1}$ at $300 \mathrm{~K}$ to 3282 and $3085 \mathrm{~cm}^{-1}$ at
$80 \mathrm{~K}$, while $\delta \mathrm{NH}_{2}$ shows softening by about $10 \mathrm{~cm}^{-1}$ (Table $\mathrm{S} 3$ ). This behavior points to significant rearrangement of $\mathrm{HBs}$ at the phase transition. Fourth, for a single $\mathrm{Pyr}^{+}$cation, only six modes related to the $\mathrm{NH}_{2}$ group are expected $\left(2 \nu \mathrm{NH}_{2}, \delta \mathrm{NH}_{2}\right.$, $\omega \mathrm{NH}_{2}, \tau \mathrm{NH}_{2}$, and $\rho \mathrm{NH}_{2}$ modes). The presence of four $\nu \mathrm{NH}_{2}$, two $\omega \mathrm{NH}_{2}$, and two $\rho \mathrm{NH}_{2}$ modes suggests either the presence of two unique $\mathrm{Pyr}^{+}$cations in the LT phase or strong Davydov splitting.

Thermal Behavior. DSC has been performed to follow heat anomalies in $\mathrm{Pyr}_{2} \mathrm{KCr}(\mathrm{CN})_{6}$. As shown in Figure 3a, a
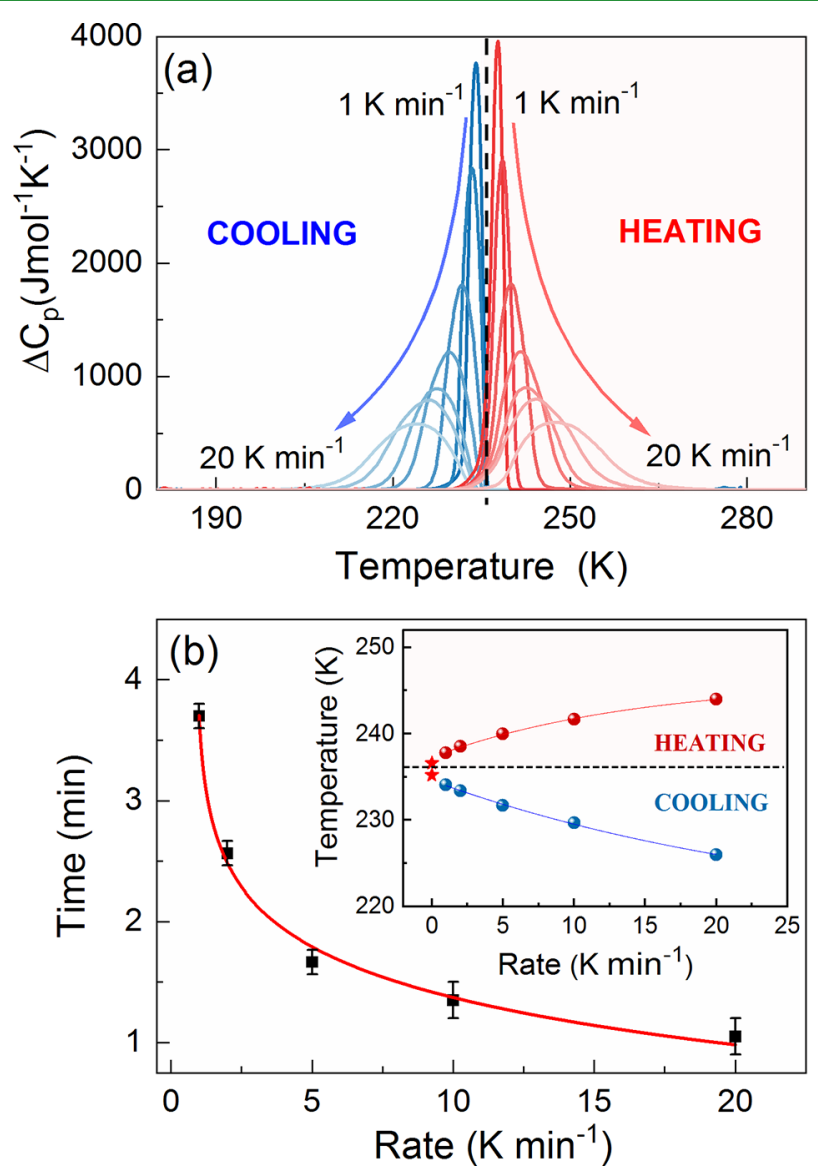

Figure 3. (a) Temperature dependences of $\Delta C_{p}$ registered on heating and cooling at the rates in between 1 and $20 \mathrm{~K} \mathrm{~min}^{-1}$ for $\mathrm{Pyr}_{2} \mathrm{KCr}(\mathrm{CN})_{6}$. (b) Time required to overcome the temperature hysteresis between heating and cooling cycles at various temperature variation rates. The inset shows the phase transition temperature evolution when altering the scanning rate.

single heat anomaly is detectable on each collected thermogram presented as a $\Delta C_{p}(T)$, i.e., excess heat capacity calculated from the DSC data. Its symmetric shape indicates that the phase transition is of the first-order type. Very large changes of enthalpy $\left(\Delta H=9.9 \mathrm{~kJ} \mathrm{~mol}^{-1}\right)$ and entropy $(\Delta S=$ $42.4 \mathrm{~kJ} \mathrm{~mol}^{-1} \mathrm{~K}^{-1}$, Figure S6) both point to an order-disorder character of the phase transition. For an order-disorder transition, $\Delta S=R \ln (N)$, where $R$ is the gas constant and $N$ is the ratio of the number of configurations in the disordered and ordered phases. The estimated $N$ value associated with heat anomalies is about 15 , indicating the high-order change at the phase transition temperature. One can expect that the disorder is related to the $\mathrm{Pyr}^{+}$cations. It is worth noting that the $\Delta S$ value of $\operatorname{Pyr}_{2} \mathrm{KCr}(\mathrm{CN})_{6}$ perovskite is about three times larger 
(a)
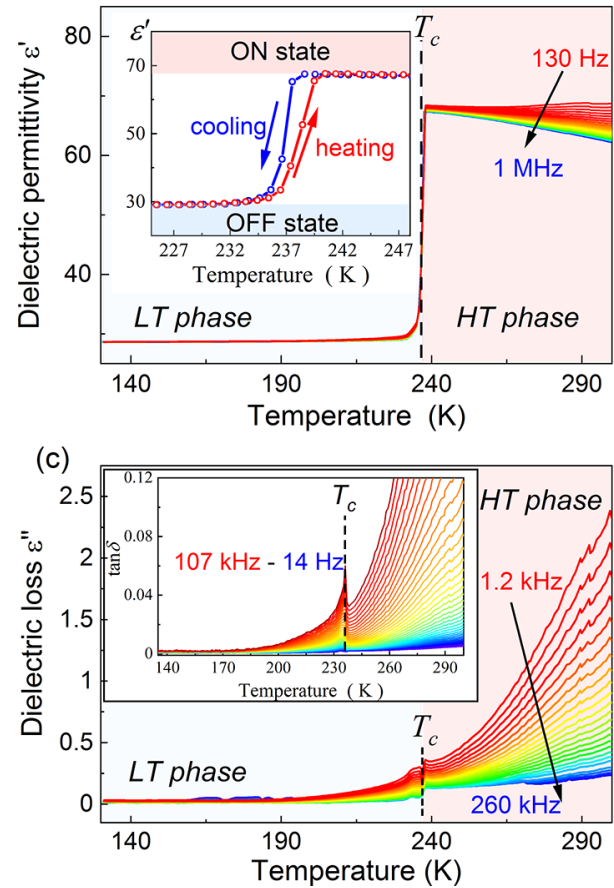

(b)

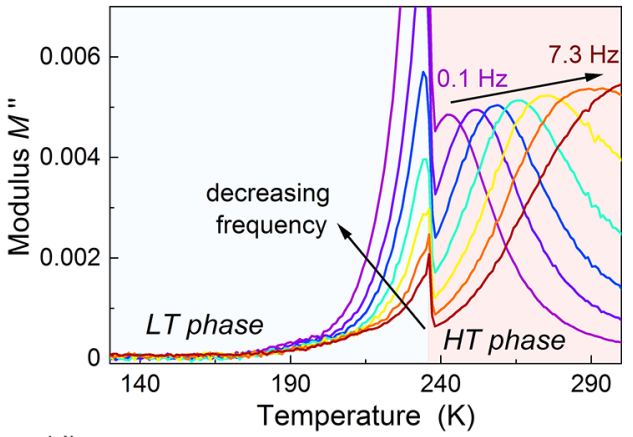

(d)

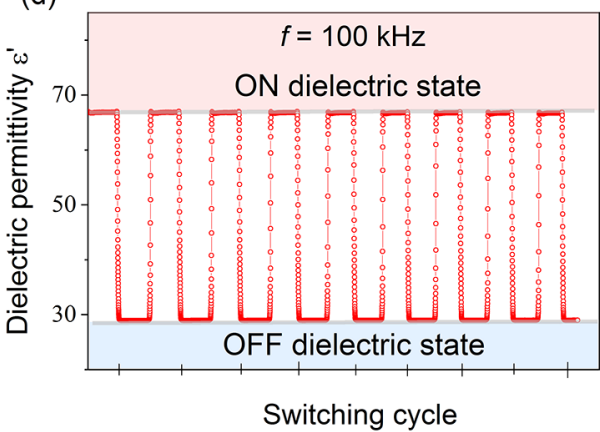

Figure 4. (a) Temperature dependence of $\varepsilon^{\prime}$ registered in between $130 \mathrm{~Hz}$ and $1 \mathrm{MHz}$ while heating. The inset shows a comparison of $\varepsilon^{\prime}(T)$ between heating and cooling cycles. (b) Temperature dependence of $M^{\prime \prime}$ registered in between 0.1 and $7.3 \mathrm{~Hz}$ while heating. (c) Thermal evolution of $\varepsilon^{\prime \prime}$ registered on heating. The inset shows $\tan \delta(T)$ dependence. (d) $\varepsilon^{\prime}$ changes with the periodic variation of temperature between 245 and 225 K.

than for nonperovskite $\mathrm{Pyr}_{2} \mathrm{KM}(\mathrm{CN})_{6}(\mathrm{M}=\mathrm{Co}$ or $\mathrm{Fe})$ analogues that exhibit phase transition from the ordered LT $P 2_{1} / c$ phase to the HT disordered $R \overline{3} m$ phase. ${ }^{48}$ Thus, DSC data indicate that the disorder of $\mathrm{Pyr}^{+}$cations is significantly larger in the $\mathrm{HT}$ phase of perovskite $\mathrm{Pyr}_{2} \mathrm{KCr}(\mathrm{CN})_{6}$ compared to nonperovskite $\mathrm{Pyr}_{2} \mathrm{KM}(\mathrm{CN})_{6}$ analogues.

The anomaly occurs at 237.8 and $234.1 \mathrm{~K}$ on heating and cooling with a rate of $1 \mathrm{~K} \mathrm{~min}^{-1}$, respectively. Hence, there is a temperature hysteresis of $3.7 \mathrm{~K}$ between both cycles, which takes as long as $3.7 \mathrm{~min}$ to overcome. To reduce the switching time, one should consider (i) applying pressure or (ii) changing the temperature variation rate. The first option has already been tested on $\mathrm{Pyr}_{2} \mathrm{KCo}(\mathrm{CN})_{6}$, the nonperovskite cobalt analogue of the herein studied hybrid compound. ${ }^{49}$ Unfortunately, growing mechanical stresses in the material triggered several undesirable pressure-induced effects, such as the increase in hysteresis under compression or time requirement modification for the switching downward only. Therefore, we consider the latter solution in this article.

As shown in the inset of Figure $3 b$, the increase in the temperature variation rate modifies the phase transition temperature in a nonlinear way. Eventually, it occurs at 244 and $226 \mathrm{~K}$ during heating and cooling at $20 \mathrm{~K} \mathrm{~min}^{-1}$. Although the temperature hysteresis increases considerably up to $18 \mathrm{~K}$, the time requirement to overcome it $\left(t_{\text {req }}=\frac{\Delta T}{\mathrm{~d} T / \mathrm{d} t}\right.$, where $\Delta T$ is the temperature hysteresis value and $\mathrm{d} T / \mathrm{d} t$ is the temperature variation rate) diminishes exponentially (Figure $3 b)$. Therefore, the pace of the temperature-controlled structural transformation (and related dielectric and THG switching processes discussed in the further paragraphs) can be easily tuned by changing the temperature variation rate. Nevertheless, according to the performed calorimetric studies, the temperature hysteresis value is critical in regulating the switching time.

We also studied the thermal stability of $\operatorname{Pyr}_{2} \mathrm{KCr}(\mathrm{CN})_{6}$. Thermogravimetric data indicate that $\operatorname{Pyr}_{2} \mathrm{KCr}(\mathrm{CN})_{6}$ starts to decompose near $485 \mathrm{~K}$ (Figure S7). The weight loss between 485 and $645 \mathrm{~K}$ is about $49 \%$ and corresponds well to complete removal of pyrrolidinium cyanide (the calculated weight loss for decomposition of $\operatorname{Pyrr}_{2} \mathrm{KCr}(\mathrm{CN})_{6}$ into pyrrolidinium, potassium, and chromium cyanides is $50.2 \%)$. The stability of this double cyanide is larger than the stability of $\mathrm{TMAO}_{2} \mathrm{KCo}(\mathrm{CN})_{6}$ and $\mathrm{TMAO}_{2} \mathrm{KFe}(\mathrm{CN})_{6}(\mathrm{TMAO}=$ $\left.\left(\mathrm{CH}_{3}\right)_{3} \mathrm{NOH}^{+}\right)$, which start to decompose at 454 and $408 \mathrm{~K}$, respectively. ${ }^{72}$ Its stability is, however, comparable to the stability of other chromium-based cyanides such as $\mathrm{DMA}_{2} \mathrm{KCr}$ $(\mathrm{CN})_{6}(483 \mathrm{~K})^{50}$ or $\mathrm{MA}_{2} \mathrm{KCr}(\mathrm{CN})_{6}(470 \mathrm{~K}) .^{39}$

Dielectric Studies. The temperature dependence of $\varepsilon^{\prime}$, registered for a single crystal and presented in Figure $4 \mathrm{a}$ between $100 \mathrm{~Hz}$ and $1 \mathrm{MHz}$, reveals a typical image of the socalled dielectric switching. As indicated in the inset of Figure $4 \mathrm{a}$, this process is fully reversible. Taking the LT phase as a starting point, $\varepsilon^{\prime}$ almost does not vary with temperature up to $236 \mathrm{~K}$, being close to 29 , regardless of the selected frequency. This value can be associated with the low (off) dielectric state. During the structural transformation to the HT phase around $238 \mathrm{~K}, \varepsilon^{\prime}$ increases rapidly by 38.5 (133\%) up to 67.5 independently of the applied frequency. As presented in Table 1 , the $\varepsilon^{\prime}$ value in the HT phase $\operatorname{Pyr}_{2} \operatorname{KCr}(\mathrm{CN})_{6}$ is higher relative to other hybrid organic-inorganic cyanides. Moreover, the change in $\varepsilon^{\prime}$ at $T_{0}\left(\Delta \varepsilon^{\prime}\right)$ is much larger compared to numerous metal-cyanide frameworks of both perovskite and nonperovskite architecture. For example, the nonperovskite pyrrolidinium-based $\operatorname{Pyr}_{2} \mathrm{KM}(\mathrm{CN})_{6}(\mathrm{M}=\mathrm{Co}$ or $\mathrm{Fe})$ analogues are characterized by $\Delta \varepsilon^{\prime}$ values equal to only 6.6 and 7.4 along 
Table 1. The Values of the $\Delta \varepsilon^{\prime}$ Parameter and $\varepsilon^{\prime}$ in the Disordered HT Phase for Selected Hybrid Cyanides Measured at the Megahertz Range

\begin{tabular}{|c|c|c|c|c|c|}
\hline \multirow[b]{2}{*}{ material } & \multicolumn{3}{|c|}{ disordered HT phase } & \multirow[b]{2}{*}{$\Delta \varepsilon^{\prime}$} & \multirow[b]{2}{*}{ ref. } \\
\hline & SG & direction & $\varepsilon^{\prime}$ & & \\
\hline $\mathrm{Pyr}_{2} \mathrm{KCr}(\mathrm{CN})_{6}$ & $F m \overline{3} m$ & {$[001]$} & 67.5 & 38.5 & this work \\
\hline $\mathrm{Pyr}_{2} \mathrm{KCo}(\mathrm{CN})_{6}$ & $R \overline{3} m$ & {$[011]$} & 23 & 6.6 & 48 \\
\hline $\mathrm{Pyr}_{2} \mathrm{KFe}(\mathrm{CN})_{6}$ & $R \overline{3} m$ & {$[011]$} & 24 & 7.4 & 48 \\
\hline \multirow[t]{2}{*}{$\mathrm{DMA}_{2} \mathrm{KCr}(\mathrm{CN})_{6}$} & $P 4 / m n c$ & {$[001]$} & 26 & 23 & 50 \\
\hline & & {$[110]$} & 15 & 12 & \\
\hline \multirow[t]{2}{*}{$\mathrm{DMA}_{2} \mathrm{KCo}(\mathrm{CN})_{6}$} & $P 4 / m n c$ & {$[001]$} & 19 & 15 & 40 \\
\hline & & {$[110]$} & 14 & 10 & \\
\hline \multirow[t]{3}{*}{$\mathrm{MA}_{2} \mathrm{KCo}(\mathrm{CN})_{6}$} & $F m \overline{3} m$ & {$[010]$} & 47 & 30 & 42 \\
\hline & & {$[101]$} & 16 & 10 & \\
\hline & & {$[111]$} & 15 & 11 & \\
\hline \multirow[t]{2}{*}{$\mathrm{HIm}_{2} \mathrm{KFe}(\mathrm{CN})_{6}$} & $R \overline{3} m$ & {$[1 \overline{2} 10]$} & 27 & 21 & 46 \\
\hline & & {$[0001]$} & 7 & 1 & \\
\hline \multirow[t]{2}{*}{$\mathrm{HIm}_{2} \mathrm{KCo}(\mathrm{CN})_{6}$} & $R \overline{3} m$ & {$[101]$} & 22 & 16 & 73 \\
\hline & & {$[001]$} & 6 & 1 & \\
\hline
\end{tabular}

the [011] direction although they contain the same cage cation. ${ }^{48,49}$ Despite that large difference, the mechanism of the dielectric switching process in $\operatorname{Pyr}_{2} \mathrm{KCr}(\mathrm{CN})_{6}$ remains the same as for the pyrrolidinium-based analogues, i.e., relies on liberation of the $\mathrm{Pyr}^{+}$motions during the order-disorder transition. This statement is evidenced by the imaginary $M^{\prime \prime}$ part of the complex dielectric modulus (Figure $4 b$ ). Specifically, its temperature dependence is characterized by a single relaxation process in the HT phase, whereas only a simple exponential decrease with lowering the temperature is detectable below $T_{0}$. According to the literature, the source of the relaxation phenomena lies in the orientational freedom of the molecular cations in the cage-like lattice. Hence, the performed studies show that the activation of more motional possibilities through architecture changes to perovskite-like allows one to tune the dielectric switching parameters in hybrid compounds effectively.

To provide a more detailed explanation of this statement, one should consider factors affecting the $\Delta \varepsilon^{\prime}$ parameter for switchable dielectrics. First, it depends on the cage cation type, increasing with its dipole moment value. Second, the $\Delta \varepsilon^{\prime}$ value is direction-dependent (see Table 1), being highly influenced by the mechanism of the cage cation motion. Little to no change in $\varepsilon^{\prime}$ at $T_{0}$ is expected for those directions, for which the spatial rearrangement of the cage cations and their dipole moment vector is forbidden. ${ }^{73}$ Consequently, it is easier to encounter the desired direction with the highest $\Delta \varepsilon^{\prime}$ for compounds with a higher number of rearrangement possibilities of the cage cations. Indeed, such a situation is observed for $\operatorname{Pyr}_{2} \mathrm{KCr}(\mathrm{CN})_{6}$, the HT phase of which is more disordered concerning the pyrrolidinium cations compared to its nonperovskite analogues. Hence, to effectively tune the switchable features in hybrid compounds, one should search for the most disordered structures containing reorientable cage cations with the highest possible dipole moment value.

Figure $4 \mathrm{c}$ displays $\tan \delta(T)$ and $\varepsilon^{\prime \prime}(T)$ plots, which show a discontinuous anomaly at $236 \mathrm{~K}$, connected with the structural transformation between LT and HT phases. However, contrary to $M^{\prime \prime}$, no relaxation processes are detectable in both representations. In general, these two quantities increase during heating because of the growing electrical conductivity contribution. Nevertheless, $\mathrm{Pyr}_{2} \mathrm{KCr}(\mathrm{CN})_{6}$ offers low dielectric losses in both phases (depicted in the inset of Figure $4 \mathrm{c}$ as low $\tan \delta$ values), which is a highly desired feature for dielectrics from an application point of view.

Apart from the dielectric switching and low dielectric loss, $\mathrm{Pyr}_{2} \mathrm{KCr}(\mathrm{CN})_{6}$ offers another much coveted feature from an application point of view, which is excellent resistance to fatigue upon multiple switching cycles. To test this property, the temperature was varied between 245 and $225 \mathrm{~K}$ periodically so that the dielectric switching between off and on states could be triggered. As depicted in Figure $4 d$, the $\varepsilon^{\prime}$ values of the off and on states were stable in time at the constant-temperature regime and remain unchanged upon numerous cycles. The fast time response of $\operatorname{Pyr}_{2} \mathrm{KCr}(\mathrm{CN})_{6}$ to temperature variation is also preserved. Consequently, the presented analysis allows us to classify $\operatorname{Pyr}_{2} \mathrm{KCr}(\mathrm{CN})_{6}$ as a lowloss switchable hybrid inorganic-organic compound, offering a significant change in $\varepsilon^{\prime}$ at $T_{\mathrm{c}}$ and a good resistance to fatigue.

Switching of THG Response. Switchable features of $\mathrm{Pyr}_{2} \mathrm{KCr}(\mathrm{CN})_{6}$ are also demonstrated in its nonlinear optical properties. Interestingly, this compound shows no SHG, but the intensity of its THG signal centered at $450 \mathrm{~nm}$ significantly changes $(10-12 \%)$ upon crossing the phase transition temperature. The first feature, i.e., no emission of SHG radiation at $675 \mathrm{~nm}$ under irradiation with $1350 \mathrm{~nm}$ femtosecond laser pulses, confirms the centrosymmetric space groups of both LT and HT phases. In turn, the latter property seems to be unique to $\operatorname{Pyr}_{2} \mathrm{KCr}(\mathrm{CN})_{6}$ since the analogous experiment for $\mathrm{Pyr}_{2} \mathrm{KCo}(\mathrm{CN})_{6}$ shows that the change in THG around $T_{0}$ is basically insignificant (Figure S8). This feature indicates a particular role of the $\mathrm{Cr}^{3+}$ center in the investigated phase transition. Therefore, we used this opportunity to study unusual temperature-dependent THG response for $\operatorname{Pyr}_{2} \mathrm{KCr}(\mathrm{CN})_{6}$ systematically. To this end, we have monitored THG signal evolution during cooling and heating cycles for four different $\mathrm{d} T / \mathrm{d} t$ rates $(20,10,5$, and $2 \mathrm{~K}$ $\left.\min ^{-1}\right)$. As presented in Figure 5a, the width of the temperature hysteresis loop significantly widens as the heating rate increases, in line with calorimetric studies.

With the above dataset in hand, we proceeded to evaluate the THG switching performance. Boundary temperature points were chosen taking into account the hysteresis widths for each heating/cooling rate, in order to ensure complete conversion into the desired crystal phase. Results for the fastest $d T / d t$ switching rate of $10 \mathrm{~K} \mathrm{~min}^{-1}$ are presented in Figure $5 \mathrm{~b}$, whereas those for rates of 2 and $5 \mathrm{~K} \mathrm{~min}^{-1}$ are shown in Figure S9. As seen in Figure 5b, switching between 234 and $208 \mathrm{~K}$ is reversible, and the THG signal keeps its intensity despite consecutive heating and cooling cycles. Upward and downward drifts in THG responses, noticeable over several consecutive cycles for the slowest $\mathrm{d} T / \mathrm{d} t$ rates of 2 and $5 \mathrm{~K} \mathrm{~min}^{-1}$, are not sample-related but are due to long-term laser oscillations (Figure S9).

Further, by taking minimum and maximum values of integral THG intensities obtained at boundary temperatures, one can calculate the mean contrast of the THG switch. It turns out that the obtained mean contrast ratio is $1.2: 1$. If one compares this value with values of contrast reported for the most prevalent SHG-on-SHG-off quadratic NLO switches, the obtained value may seem not really high. For instance, of the highest contrast ratios (74:1 at around $328 \mathrm{~K}$ ) was obtained by Zhang et al. for a material of the formula $\left(\mathrm{MeNHEt}_{2}\right)[\mathrm{Cd}-$ $\left.(\mathrm{SCN})_{3}\right] .^{74}$ Clearly, a high contrast of SHG-on-SHG-off quadratic NLO switches can hardly be beaten, as this kind of 

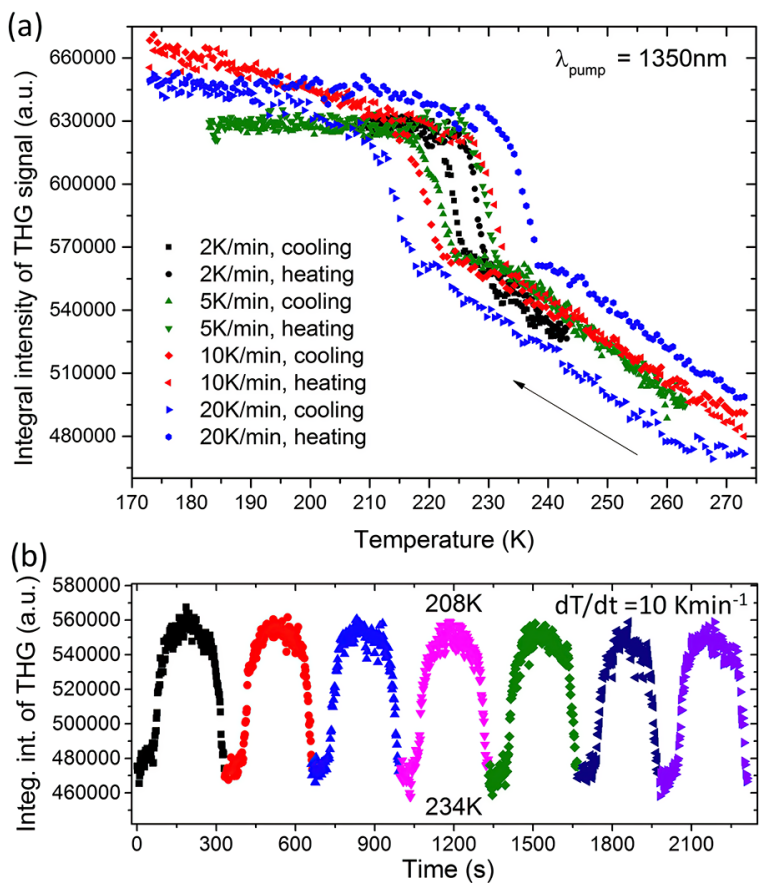

Figure 5. (a) Plots of integral intensities of the THG signal measured for four different heating/cooling rates: $2,5,10$, and $20 \mathrm{~K} \mathrm{~min}^{-1}$. (b) Plot of integral intensities of the THG signal obtained during switching experiments between 234 and $208 \mathrm{~K}$ for a heating/cooling rate of $10 \mathrm{~K} \mathrm{~min}^{-1}$. Consecutive cycles are drawn with different colors.

NLO switching essentially operates against zero (nearly zero) background.

As indicated in previous sections, $\operatorname{Pyr}_{2} \mathrm{KCr}(\mathrm{CN})_{6}$ is the first HOIP material to feature THG switching, to the best of our knowledge. For this reason, it is not possible to provide appleto-apple comparisons with similar materials. However, if we reach out to different material classes, a handful of examples of THG switching can be found in the literature. For instance, THG switching has been demonstrated for all-inorganic materials such as dichalcogenides and chalcogenide $\mathrm{Ge}-\mathrm{Sb}-$ Te alloys (glasses). One example of a dichalcogenide THG switch is $\mathrm{Sb}_{2} \mathrm{~S}_{3}$ sandwiched in between $\mathrm{SiO}_{2}$ layers. This composite, embedded in a Fabry-Pérot cavity, featured a THG contrast of 100:1 upon a phase change. ${ }^{75}$ A conceptually similar device employing $\mathrm{Ge}_{2} \mathrm{Sb}_{2} \mathrm{Te}_{5}$ revealed a difference of three orders of magnitude in THG intensity due to the phase transition. ${ }^{76}$ What needs stressing is that the phase transition occurs between crystalline and amorphous phases in these cases and explains why contrast ratios are so high for these compounds-THG for amorphous phases is practically suppressed. In this context it becomes clear why the THG contrast ratio for the title material is not as high as for the above examples-both phases of $\mathrm{Pyr}_{2} \mathrm{KCr}(\mathrm{CN})_{6}$ are crystalline.

Linear Optical Properties. The diffuse reflectance spectrum of $\operatorname{Pyr}_{2} \mathrm{KCr}(\mathrm{CN})_{6}$ shows broad bands at 314.7 $\left(31,776 \mathrm{~cm}^{-1}\right), 402.2\left(24,863 \mathrm{~cm}^{-1}\right)$, and $528.7 \mathrm{~nm}(18,914$ $\mathrm{cm}^{-1}$ ) (Figure $\mathrm{S} 10$ ) that can be assigned to electron transitions from the ${ }^{4} \mathrm{~A}_{2 \mathrm{~g}}$ ground level to ${ }^{4} \mathrm{~T}_{1 \mathrm{~g},}{ }^{4} \mathrm{~T}_{2 \mathrm{~g}}$, and ${ }^{2} \mathrm{~T}_{2 \mathrm{~g}}$ excited states of $\mathrm{Cr}^{3+}$, respectively. ${ }^{77}$ It is worth noting that the positions of these bands are strongly blueshifted compared to typical absorption bands of $\mathrm{Cr}^{3+}$ coordinated to oxygen ions. ${ }^{78-81}$ The observed blueshift results from a strong crystal field around chromium ions, which are coordinated by the cyanide groups
$(\mathrm{Cr}-\mathrm{C} \equiv \mathrm{N}-\mathrm{K})$. Due to the low absorption cross section, the zero-phonon line of ${ }^{2} \mathrm{E}_{\mathrm{g}}$ has not been detected. $\operatorname{Pyr}_{2} \mathrm{KCo}(\mathrm{CN})_{6}$ samples doped with $\mathrm{Cr}^{3+}$ show broad bands at $317.3(31,516$ $\left.\mathrm{cm}^{-1}\right)$ and $400.4 \mathrm{~nm}\left(24,975 \mathrm{~cm}^{-1}\right)$ that can be attributed to electron transitions from the ${ }^{1} \mathrm{~A}_{1 \mathrm{~g}}$ ground level to ${ }^{1} \mathrm{~T}_{1 \mathrm{~g}}$ and ${ }^{3} \mathrm{~T}_{1 \mathrm{~g}}$ excited states of $\mathrm{Co}^{3+}$, respectively. ${ }^{82}$ These bands overlap with weaker ${ }^{4} \mathrm{~A}_{2 \mathrm{~g}} \rightarrow{ }^{4} \mathrm{~T}_{1 \mathrm{~g}}$ and ${ }^{4} \mathrm{~A}_{2 \mathrm{~g}} \rightarrow{ }^{4} \mathrm{~T}_{2 \mathrm{~g}}$ bands related to $\mathrm{Cr}^{3+}$.

As can be seen in Figure 6, the emission bands of $\mathrm{Cr}^{3+}$ ions in the investigated compounds can be assigned to spin-

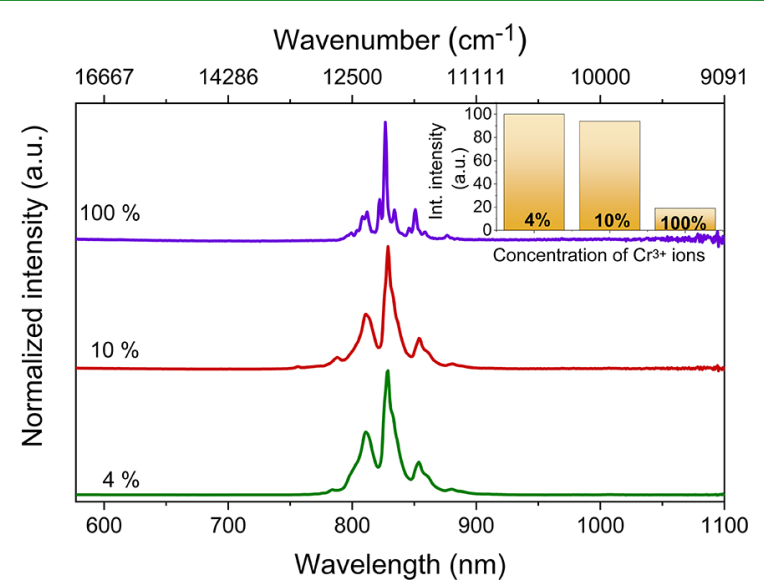

Figure 6. Normalized PL spectra of $\mathrm{Pyr}_{2} \mathrm{KCr}(\mathrm{CN})_{6}$ and $\mathrm{Pyr}_{2} \mathrm{KCo}$ $(\mathrm{CN})_{6}$ doped with 4 and $10 \% \mathrm{Cr}^{3+}$ ions at $77 \mathrm{~K}$. The inset shows the influence of $\mathrm{Cr}^{3+}$ ion concentration on the PL intensity.

forbidden ${ }^{2} \mathrm{E}_{\mathrm{g}} \rightarrow{ }^{4} \mathrm{~A}_{2 \mathrm{~g}}$ transitions. However, a very rich band structure makes the explanation of the individual bands' origin not trivial. Based on the literature data on inorganic cyanides comprising $\mathrm{Cr}^{3+77,83,84}$ as well as the phosphorescence spectra of $\mathrm{Pyr}_{2} \mathrm{KCr}(\mathrm{CN})_{6}$ measured at $5 \mathrm{~K}$ (Figure S11), the band at around $12,438 \mathrm{~cm}^{-1}(804 \mathrm{~nm})$ was assigned to the $0-0$ phonon line called $\mathrm{R}_{1}$. In the case of the $\operatorname{Pyr}_{2} \mathrm{KCo}(\mathrm{CN})_{6}: \mathrm{Cr}^{3+}$ samples, this line is observed near $12,500 \mathrm{~cm}^{-1}(800 \mathrm{~nm})$. It is important to emphasize that the observed phosphorescence is very strongly redshifted compared to the phosphorescence of oxide materials (typically near $700 \mathrm{~nm}$ ) or even compared to molecular $\mathrm{Cr}^{3+}$ complexes $\left(\lambda_{\text {em }} \text { below } 777 \mathrm{~nm}\right)^{19,20}$ due to the strong crystal field around the chromium ions. In addition to the $\mathrm{R}_{1}$ line, many narrow bands are observed for $\mathrm{Pyr}_{2} \mathrm{KCr}$ $(\mathrm{CN})_{6}$ on the low-energy side of this line. A majority of these bands can be assigned to vibronic transitions, but some of them may probably be attributed to $\mathrm{N}$ lines since the presence of $\mathrm{N}$ lines has been observed for many compounds heavily doped with $\mathrm{Cr}^{3+}$ and classified as the emission of chromium pairs $\left(\mathrm{Cr}^{3+}-\mathrm{Cr}^{3+}\right) \cdot{ }^{80,81,85}$ It can be noticed that the narrow bands form three major groups visible in the 808-812, 821834 , and $845-858 \mathrm{~nm}$ ranges (Figure 6). Three very similar groups of bands, although much less resolved, are also observed for the $\mathrm{Pyr}_{2} \mathrm{KCo}(\mathrm{CN})_{6}: \mathrm{Cr}^{3+}$ samples (Figure 6 and Figures S12-S14). In the case of inorganic cyanides, the most intense vibronic bands, shifted by less than $460 \mathrm{~cm}^{-1}$ with respect to the $0-0$ phonon line, were attributed to IR-active fundamental vibrations of a metal-cyanide framework. ${ }^{83}$ On the other hand, weaker vibronic bands shifted by more than $500 \mathrm{~cm}^{-1}$ could be explained as arising from vibrational combination modes. By analogy with inorganic cyanides, we can attribute the three mentioned above groups of bands, shifted by about $60-130,270-450$, and $600-800 \mathrm{~cm}^{-1}$ with respect to the $\mathrm{R}_{1}$ line, to the $\nu_{9}$ and $\nu_{13}$ fundamental modes, $\nu_{7}$, 
Table 2. Transition Energies, the Ligand Field Strength Parameter $D q$, and the Racah $\operatorname{Parameter}$ for $\operatorname{Pyr}{ }_{2} \mathrm{KCr}(\mathrm{CN})_{6}$

\begin{tabular}{|c|c|c|c|c|c|c|c|}
\hline & transition & & & & & & \\
\hline${ }^{4} \mathrm{~A}_{2 \mathrm{~g}} \rightarrow{ }^{4} \mathrm{~T}_{2 \mathrm{~g}}$ & ${ }^{4} \mathrm{~A}_{2 \mathrm{~g}} \rightarrow{ }^{4} \mathrm{~T}_{1 \mathrm{~g}}$ & ${ }^{4} \mathrm{~A}_{2 \mathrm{~g}} \rightarrow \mathrm{E}_{\mathrm{g}}$ & $D q$ & $B$ & C & $D q / B$ & $C / B$ \\
\hline 24,863 & 31,776 & 12,438 & 2486 & 637 & 2524 & 3.9 & 3.96 \\
\hline
\end{tabular}

$\nu_{8}$, and $\nu_{12}$ fundamental modes, and combination modes, respectively, of the $\mathrm{Cr}(\mathrm{CN})_{6}$ units. $^{83}$ However, due to lack of temperature-dependent IR data in the far-infrared range, a more detailed assignment of vibronic bands could not be proposed.

The inset in Figure 6 presents the effect of $\mathrm{Cr}^{3+}$ concentration on the PL intensity. The highest intensity is observed for the sample containing the lowest concentration of $\mathrm{Cr}^{3+}$ ions, while the PL intensity of the $\operatorname{Pyr}_{2} \mathrm{KCr}(\mathrm{CN})_{6}$ sample is about 5 times lower. This effect can be related to the concentration quenching processes.

Crystal field $(D q)$ and Racah $(B)$ parameters were calculated for the investigated compounds from the diffuse reflectance absorption and emission spectra. The value of the $B$ parameter was found by setting the determinant (where $T_{\mathrm{F}}$ is the energy of the ${ }^{4} \mathrm{~T}_{1}(\mathrm{~F})$ band) defined below equal to 0 .

$$
\left|\begin{array}{cc}
10 D q+12 B-T_{\mathrm{F}} & 6 B \\
6 B & 20 D q+3 B-T_{\mathrm{F}}
\end{array}\right|
$$

The transition energies and the calculated values of crystal field parameters are presented in Table 2 . The $D q / B$ parameter is equal to 3.9 for $\operatorname{Pyr}_{2} \mathrm{KCr}(\mathrm{CN})_{6}$. The value of $\mathrm{Dq} / B$ higher than 2.3 confirms a strong crystal field in the immediate vicinity of $\mathrm{Cr}^{3+}$ ions. Obtained crystal field parameters and transition energies are similar to the values reported for $\mathrm{K}_{3}\left[\mathrm{Cr}_{x} \mathrm{Co}_{1-x}(\mathrm{CN})_{6}\right] .^{77}$ However, the calculated $\mathrm{Dq}$ and Racah parameters are much higher than for recently reported formate perovskites. $^{78-80}$

Temperature-dependent emission spectra of $\mathrm{Pyr}_{2} \mathrm{KCo}(\mathrm{CN})_{6}$ doped with $4 \% \mathrm{Cr}^{3+}$ ions are presented in Figure S13. Under $266 \mathrm{~nm}$ excitation, the sample shows strong PL bands related to the spin-forbidden transition of $\mathrm{Cr}^{3+}$ ions and low-intensity bands related to the $\vec{\pi} \pi^{*}$ ligand transition. The latter bands are observed in the 400-700 $\mathrm{nm}$ range (see the inset in Figure S13). Due to the fact that the host emission overlaps with ${ }^{4} \mathrm{~T}_{2 \mathrm{~g}}$ and ${ }^{2} \mathrm{~T}_{2 \mathrm{~g}}$ absorption bands of $\mathrm{Cr}^{3+}$ ions, the probability of the reabsorption process increases with the dopant content. It can be seen that the PL related to the spin-forbidden transition of $\mathrm{Cr}^{3+}$ ions is stable with the temperature both for $\mathrm{Pyr}_{2} \mathrm{KCo}$ $(\mathrm{CN})_{6}: \mathrm{Cr}^{3+}$ and $\mathrm{Pyr}_{2} \mathrm{KCr}(\mathrm{CN})_{6}$ (Figure 7 and Figures S13 and S14). However, broadening of the PL bands with heating the samples is observed. Temperature-dependent studies of $\mathrm{Pyr}_{2} \mathrm{KCr}(\mathrm{CN})_{6}$ also show an increase in PL intensity as well as splitting of bands near $220-230 \mathrm{~K}$, which can be related to the phase transition occurring near $235 \mathrm{~K}$.

\section{CONCLUSIONS}

The foregoing results demonstrate an effective strategy to obtain a temperature-switchable material with divergent, thirdorder nonlinear optical and dielectric switching modes. The application of $\mathrm{Cr}^{3+}$ as metal nodes for construction of a metalcyanide network affords interstitial sites big enough to accommodate large pyrrolidinium organic cations. As a result, $\mathrm{Pyr}_{2} \mathrm{KCr}(\mathrm{CN})_{6}$ distinguishes itself in terms of temperatureinduced switching stability, much improved compared to $\mathrm{Cr}^{3+}$ analogues comprising other organic cations or strained

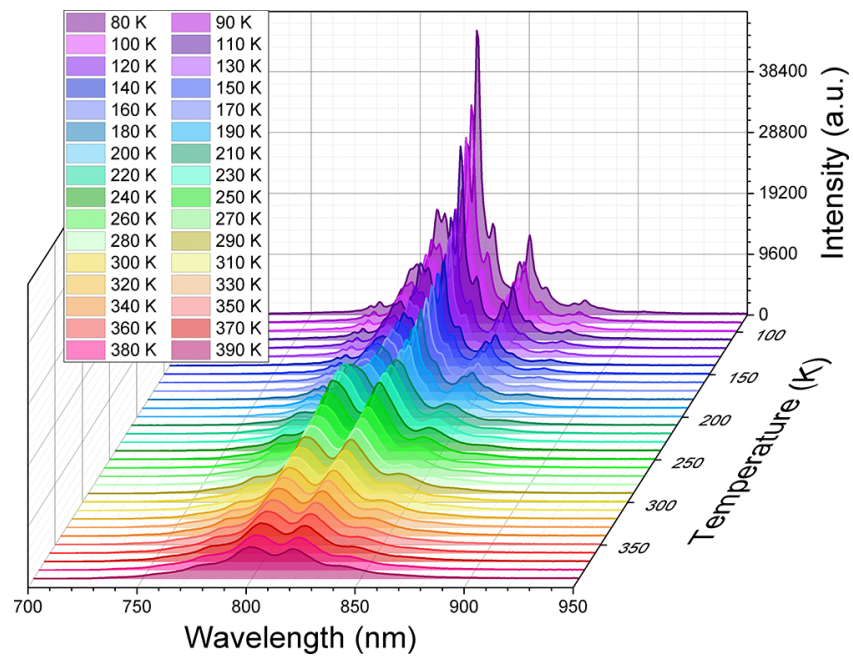

Figure 7. Temperature-dependent $\mathrm{PL}$ spectra of $\mathrm{Pyr}_{2} \mathrm{KCr}(\mathrm{CN})_{6}$ under $266 \mathrm{~nm}$ excitation.

analogue materials comprising smaller $\mathrm{Co}^{3+}$ or $\mathrm{Fe}^{3+}$ ions. The other beneficial outcome for temperature switching capability is that $\mathrm{Pyr}^{+}$cations experience enhanced reorientational freedom in the HT phase, making dielectric switching possible with a huge change in the dielectric permittivity value $\left(\Delta \varepsilon^{\prime}=38.5\right)$ during the order-disorder structural transition at around $238 \mathrm{~K}$.

Despite the fact that THG occurs in any crystalline solid, THG switching has never been reported for HOIP materials. In this contribution, we have demonstrated proof of concept of the reversible temperature switching of THG response, as well as for the first applied THG spectroscopy to track the phase transition in general. We thus expect a new field of THG switching in HOIPs to emerge soon.

We also demonstrate that $\mathrm{Pyr}_{2} \mathrm{KCr}(\mathrm{CN})_{6}$ exhibits strongly redshifted NIR phosphorescence, extending from 770 to 880 $\mathrm{nm}$. The unprecedentedly large redshift can be attributed to the very large crystal field strength $(D q / B=3.9)$. Nonperovskite $\mathrm{Pyr}_{2} \mathrm{KCo}(\mathrm{CN})_{6}$ doped with $\mathrm{Cr}^{3+}$ ions also shows NIR phosphorescence. Thus, doping with $\mathrm{Cr}^{3+}$ ions is an effective way to introduce $\mathrm{PL}$ as an additional functional property to the family of cobalt-cyanide switchable dielectrics. Furthermore, NIR PL can be tuned by alloying of chromium and cobalt cyanides as well as use of various alkali metal and organic cations.

We also envision that $\mathrm{Cr}^{3+}$-based extension of cyanide networks will make synthesis of $3 \mathrm{D}$ perovskite cyanide networks accommodating very large organic cations such as thiazolium, tropylium, and the like possible. Therefore, our results pave the way to new cyanide-based perovskites and show how to merge and effectively tune the switchable dielectric, THG, and NIR PL properties much desired in sensing, bioimaging, and optoelectronic applications. 


\section{ASSOCIATED CONTENT}

\section{s) Supporting Information}

The Supporting Information is available free of charge at https://pubs.acs.org/doi/10.1021/acsami.1c20557.

Crystallographic data, vibrational selection rules, Raman and IR wavenumbers and assignment of modes, PXRD patterns, reciprocal space reconstruction, change in entropy at the phase transition, Raman and IR spectra, spectra of THG signals, diffuse reflectance spectra, PL plots, and temperature-dependent decay times (PDF) CIF file for the structure at RT (CIF)

\section{AUTHOR INFORMATION}

\section{Corresponding Authors}

Mirosław Mączka - Institute of Low Temperature and Structure Research, Polish Academy of Sciences, 50-422 Wroctaw, Poland; 이이.org/0000-0003-2978-1093; Phone: +48-713954161; Email: m.maczka@intibs.pl; Fax: +48-713441029

Jan K. Zarȩba - Advanced Materials Engineering and Modeling Group, Faculty of Chemistry, Wroctaw University of Science and Technology, 50-370 Wroctaw, Poland; ○ orcid.org/0000-0001-6117-6876; Email: jan.zareba@ pwr.edu.pl

\section{Authors}

Andrzej Nowok - Department of Experimental Physics, Wrocław University of Science and Technology, 50-370 Wroctaw, Poland; (1) orcid.org/0000-0002-4833-4259

Dagmara Stefańska - Institute of Low Temperature and Structure Research, Polish Academy of Sciences, 50-422 Wroctaw, Poland; (1) orcid.org/0000-0002-1051-3761

Anna Ga̧gor - Institute of Low Temperature and Structure Research, Polish Academy of Sciences, 50-422 Wroctaw, Poland

Monika Trzebiatowska - Institute of Low Temperature and Structure Research, Polish Academy of Sciences, 50-422 Wroctaw, Poland

Adam Sieradzki - Department of Experimental Physics, Wroctaw University of Science and Technology, 50-370 Wroctaw, Poland; 이이이.org/0000-0003-4136-5754

Complete contact information is available at: https://pubs.acs.org/10.1021/acsami.1c20557

\section{Author Contributions}

The manuscript was written through contributions of all authors. All authors have given approval to the final version of the manuscript.

\section{Notes}

The authors declare no competing financial interest.

\section{ACKNOWLEDGMENTS}

This research was supported by the National Science Center (Narodowe Centrum Nauki) in Poland under project no. 2017/25/B/ST5/00160. J.K.Z. acknowledges support from the Academia Iuvenum, Wrocław University of Science and Technology.

\section{REFERENCES}

(1) Li, X.; Hoffman, J. M.; Kanatzidis, M. G. The 2D Halide Perovskite Rulebook: How the Spacer Influences Everything from the
Structure to Optoelectronic Device Efficiency. Chem. Rev. 2021, 121, 2230-2291.

(2) Li, W.; Wang, Z.; Deschler, F.; Gao, S.; Friend, R. H.; Cheetham, A. K. Chemically Diverse and Multifunctional Hybrid OrganicInorganic Perovskites. Nat. Rev. Mater. 2017, 2, 16099.

(3) Mączka, M.; Ptak, M.; Gạgor, A.; Stefańska, D.; Zarȩba, J. K.; Sieradzki, A. Methylhydrazinium Lead Bromide: Noncentrosymmetric Three-Dimensional Perovskite with Exceptionally Large Framework Distortion and Green Photoluminescence. Chem. Mater. 2020, 32, 1667-1673.

(4) Smith, M. D.; Connor, B. A.; Karunadasa, H. I. Tuning the Luminescence of Layered Halide Perovskites. Chem. Rev. 2019, 119, 3104-3139.

(5) Saparov, B.; Mitzi, D. B. Organic-Inorganic Perovskites: Structural Versatility for Functional Materials Design. Chem. Rev. 2016, 116, 4558-4596.

(6) Han, X.; Zheng, Y.; Chai, S.; Chen, S.; Xu, J. 2D OrganicInorganic Hybrid Perovskite Materials for Nonlinear Optics. NANO 2020, 9, 1787-1810.

(7) Hu, Y.; Zhang, H.; Chong, W. K.; Li, Y.; Ke, Y.; Ganguly, R.; Morris, S. A.; You, L.; Yu, T.; Sum, T. C.; Long, Y.; Fan, H. J. Molecular Engineering toward Coexistence of Dielectric and Optical Switch Behavior in Hybrid Perovskite Phase Transition Material. J. Phys. Chem. A 2018, 122, 6416-6423.

(8) Ye, H. Y.; Zhou, Q.; Niu, X.; Liao, W. Q.; Fu, D. W.; Zhang, Y.; You, Y. M.; Wang, J.; Chen, Z. N.; Xiong, R. G. High-Temperature Ferroelectricity and Photoluminescence in a Hybrid OrganicInorganic Compound: (3-Pyrrolinium) $\mathrm{MnCl}_{3}$. J. Am. Chem. Soc. 2015, 137, 13148-13154.

(9) Zhang, Y.; Liao, W.-Q.; Fu, D.-W.; Ye, H.-Y.; Liu, C.-M.; Chen, Z.-N.; Xiong, R.-G. The First Organic-Inorganic Hybrid Luminescent Multiferroic: (Pyrrolidinium) $\mathrm{MnBr}_{3}$. Adv. Mater. 2015, 27, 39423946.

(10) Liu, H.; Zhang, H.; Xu, X.; Zhang, L. The Opto-Electronic Functional Devices Based on Three-Dimensional Lead Halide Perovskites. Appl. Sci. 2021, 11, 1453.

(11) Mạczka, M.; Gạgor, A.; Zaręba, J. K.; Stefańska, D.; Drozd, M.; Balciunas, S.; Simenas, M.; Banys, J.; Sieradzki, A. Three-Dimensional Perovskite Methylhydrazinium Lead Chloride with Two Polar Phases and Unusual Second-Harmonic Generation Bistability above Room Temperature. Chem. Mater. 2020, 32, 4072-4082.

(12) Jain, P.; Stroppa, A.; Nabok, D.; Marino, A.; Rubano, A.; Paparo, D.; Matsubara, M.; Nakotte, H.; Fiebig, M.; Picozzi, S.; Choi, E. S.; Cheetham, A. K.; Draxl, C.; Dalal, N. S.; Zapf, V. S. Switchable Electric Polarization and Ferroelectric Domains in a Metal-OrganicFramework. NPJ Quant. Mater. 2016, 1, 16012.

(13) Mączka, M.; Ga̧gor, A.; Ptak, M.; Paraguassu, W.; Da Silva, T. A.; Sieradzki, A.; Pikul, A. Phase Transitions and Coexistence of Magnetic and Electric Orders in the Methylhydrazinium Metal Formate Frameworks. Chem. Mater. 2017, 29, 2264-2275.

(14) Wu, Y.; Shaker, S.; Brivio, F.; Murugavel, R.; Bristowe, P. D.; Cheetham, A. K. $\mathrm{Mn}\left(\mathrm{H}_{2} \mathrm{POO}\right)_{3}$ : A New Family of Hybrid Perovskites Based on the Hypophosphite Ligand. J. Am. Chem. Soc. 2017, 139, 16999-17002.

(15) Mączka, M.; Stefańska, D.; Ptak, M.; Gągor, A.; Pikul, A.; Sieradzki, A. Cadmium and Manganese Hypophosphite Perovskites Templated by Formamidinium Cations: Dielectric, Optical and Magnetic Properties. Dalton Trans. 2021, 50, 2639-2647.

(16) Zhou, L.; Zheng, X.; Shi, P. P.; Zafar, Z.; Ye, H. Y.; Fu, D. W.; Ye, Q. Switchable Nonlinear Optical and Tunable Luminescent Properties Triggered by Multiple Phase Transitions in a PerovskiteLike Compound. Inorg. Chem. 2017, 56, 3238-3244.

(17) Mączka, M.; Ga̧gor, A.; Stroppa, A.; Gonçalves, J. N.; Zaręba, J. K.; Stefańska, D.; Pikul, A.; Drozd, M.; Sieradzki, A. TwoDimensional Metal Dicyanamide Frameworks of BeTriMe[M$\left.(\mathrm{dca})_{3}\left(\mathrm{H}_{2} \mathrm{O}\right)\right] \quad($ BeTriMe $=$ Benzyltrimethylammonium; $\mathrm{dca}=$ Dicyanamide; $\left.\mathrm{M}=\mathrm{Mn}^{2+}, \mathrm{Co}^{2+}, \mathrm{Ni}^{2+}\right)$ : Coexistence of Polar and Magnetic Orders and Nonlinear Optical Threshold Temperature Sensing. J. Mat. Chem. C 2020, 8, 11735-11747. 
(18) Yakunin, S.; Benin, B. M.; Shynkarenko, Y.; Nazarenko, O.; Bodnarchuk, M. I.; Dirin, D. N.; Hofer, C.; Cattaneo, S.; Kovalenko, M. V. High-Resolution Remote Thermometry and Thermography Using Luminescent Low-Dimensional Tin-Halide Perovskites. Nat. Mater. 2019, 18, 846-852.

(19) Adachi, S. Review-Photoluminescence Properties of $\mathrm{Cr}^{3+}$ -Activated Oxide Phosphors. ECS J. Sol. State Sci. Technol. 2021, 10, No. 026001.

(20) Scattergood, P. A. Recent Advances in Chromium Coordination Chemistry: Luminescent Materials and Photocatalysis. In Organometallic Chemistry; Royal Society of Chemistry, 2020; Patmore, N. J.; Elliott, P., Eds.; Vol. 43, pp. 1-34.

(21) Jia, Z.; Yuan, C.; Liu, Y.; Wang, X. J.; Sun, P.; Wang, L.; Jiang, H.; Jiang, J. Strategies to Approach High Performance in $\mathrm{Cr}^{3+}$-Doped Phosphors for High-Power NIR-LED Light Sources. Light Sci. Appl. 2020, 9, 86 .

(22) Shao, Q.; Ding, H.; Yao, L.; Xu, J.; Liang, C.; Jiang, J. Photoluminescence Properties of a $\mathrm{ScBO}_{3}: \mathrm{Cr}^{3+}$ Phosphor and Its Applications for Broadband Near-Infrared LEDs. RSC Adv. 2018, 8, 12035-12042.

(23) Ptak, M.; Maczka, M.; Gagor, A.; Sieradzki, A.; Bondzior, B.; Dereń, P.; Pawlus, S. Phase Transitions and Chromium(III) Luminescence in Perovskite-Type $\left[\mathrm{C}_{2} \mathrm{H}_{5} \mathrm{NH}_{3}\right]$ $\left[\mathrm{Na}_{0.5} \mathrm{Cr}_{\mathrm{x}} \mathrm{Al}_{0.5-\mathrm{x}}(\mathrm{HCOO})_{3}\right] \quad(\mathrm{x}=0,0.025,0.5)$, Correlated with Structural, Dielectric and Phonon Properties. Phys. Chem. Chem. Phys. 2016, 18, 29629-29640.

(24) Henderson, B.; Imbusch, G. F. Optical Spectroscopy of Inorganic Solids, Oxford University Press, New York, 1989.

(25) Otto, S.; Dorn, M.; Förster, C.; Bauer, M.; Seitz, M.; Heinze, K. Understanding and Exploiting Long-Lived near-Infrared Emission of a Molecular Ruby. Coord. Chem. Rev. 2018, 359, 102-111.

(26) Büldt, L. A.; Wenger, O. S. Chromium Complexes for Luminescence, Solar Cells, Photoredox Catalysis, Upconversion, and Phototriggered NO Release. Chem. Sci. 2017, 8, 7359-7367.

(27) Lazarides, T.; Davies, G. M.; Adams, H.; Sabatini, C.; Barigelletti, F.; Barbieri, A.; Pope, S. J. A.; Faulkner, S.; Ward, M. D. Ligand-Field Excited States of Hexacyanochromate and Hexacyanocobaltate as Sensitisers for near-Infrared Luminescence from $\mathrm{Nd}(\mathrm{III})$ and $\mathrm{Yb}(\mathrm{III})$ in Cyanide-Bridged d-f Assemblies. Photochem. Photobiol. Sci. 2007, 6, 1152-1157.

(28) Kunkely, H.; Vogler, A. Optical Properties of Gd ${ }^{\mathrm{III}}\left[\mathrm{M}^{\mathrm{III}}(\mathrm{CN})_{6}\right]$ with $\mathrm{M}=\mathrm{Cr}$ and Co. Phosphorescence from Ligand-Field States of $\left[\mathrm{M}(\mathrm{CN})_{6}\right]^{3-}$ under Ambient Conditions. Inorg. Chem. Commun. 2004, $7,770-772$.

(29) Han, S.; Zhang, J.; Teng, B.; Ji, C.; Zhang, W.; Sun, Z.; Luo, J. Inorganic-Organic Hybrid Switchable Dielectric Materials with the Coexistence of Magnetic Anomalies Induced by Reversible HighTemperature Phase Transition. J. Mater. Chem. C 2017, 5, 85098515

(30) Khan, T.; Asghar, M. A.; Sun, Z.; Zeb, A.; Ji, C.; Luo, J. A Supra-Molecular Switchable Dielectric Material with Non-Linear Optical Properties. J. Mater. Chem. C 2017, 5, 2865-2870.

(31) Hua, X. N.; Gao, J. X.; Zhang, T.; Chen, X. G.; Sun, D. S.; Zhang, Y. Z.; Liao, W. Q. Switchable Dielectric Phase Transition with Drastic Symmetry Breaking in a Sn(IV)-Based Perovskite-Type Halide Semiconductor. J. Phys. Chem. C 2019, 123, 21161-21166.

(32) Zhao, X. M.; Li, D.; Zhao, H. X.; Ren, Y. P.; Long, L. S.; Zheng, L. S. Polar Molecule-Based Material with Optic-Electric Switching Constructed by Polar Anions. Inorg. Chem. 2020, 59, 5475-5482.

(33) Xue, C.; Yao, Z. Y.; Zhang, J.; Liu, W. L.; Liu, J. L.; Ren, X. M. Extra Thermo- and Water-Stable One-Dimensional Organic-Inorganic Hybrid Perovskite: [N-Methyldabconium] $\mathrm{PbI}_{3}$ Showing Switchable Dielectric Behaviour, Conductivity and Bright Yellow-Green Emission. Chem. Comm. 2018, 54, 4321-4324.

(34) Zheng, X.; Shi, P. P.; Lu, Y.; Zhou, L.; Gao, J. X.; Geng, F. J.; Wu, D. H.; Fu, D. W.; Ye, Q. Dielectric and Nonlinear Optical Dual Switching in an Organic-Inorganic Hybrid Relaxor $\left[\left(\mathrm{CH}_{3}\right)_{3} \mathrm{PCH}_{2} \mathrm{OH}\right]\left[\mathrm{Cd}(\mathrm{SCN})_{3}\right]$. Inorg. Chem. Front. 2017, 4, 1445-1450.
(35) Sui, Y.; Wang, L.-J.; Lai, H.-Q.; Ma, Y.-X.; Jiang, Y.-L.; Liu, D.S. High-Temperature Switchable Dielectric of an Organic-Inorganic Hybrid Metal Halide with Four-Fold Cross-Linking Inorganic Anion Spiral Chains. ACS Appl. El. Mater. 2020, 2, 1421-1425.

(36) Du, Z.-Y.; Xu, T.-T.; Huang, B.; Su, Y.-J.; Xue, W.; He, C.-T.; Zhang, W.-X.; Chen, X.-M. Switchable Guest Molecular Dynamics in a Perovskite-Like Coordination Polymer toward Sensitive Thermoresponsive Dielectric Materials. Angew. Chem., Int. Ed. 2015, 54, 914918.

(37) Trzebiatowska, M.; Maczka, M.; Ptak, M.; Giriunas, L.; Balciunas, S.; Simenas, M.; Klose, D.; Banys, J. Spectroscopic Study of Structural Phase Transition and Dynamic Effects in a $\left[\left(\mathrm{CH}_{3}\right)_{2} \mathrm{NH}_{2}\right]$ $\left[\mathrm{Cd}\left(\mathrm{N}_{3}\right)_{3}\right]$ Hybrid Perovskite Framework. J. Phys. Chem. C 2019, 123, 11840-11849.

(38) Mạczka, M.; Ptak, M.; Ga̧gor, A.; Sieradzki, A.; Peksa, P.; Usevicius, G.; Simenas, M.; Leite, F. F.; Paraguassu, W. Temperatureand Pressure-Dependent Studies of a Highly Flexible and Compressible Perovskite-like Cadmium Dicyanamide Framework Templated with Protonated Tetrapropylamine. J. Mat. Chem. C 2019, 7, 24082420.

(39) Rok, M.; Moskwa, M.; Działowa, M.; Bieńko, A.; Rajnák, C.; Boča, R.; Bator, G. Multifunctional Materials Based on the DoublePerovskite Organic-Inorganic Hybrid $\left(\mathrm{CH}_{3} \mathrm{NH}_{3}\right)_{2}\left[\mathrm{KCr}(\mathrm{CN})_{6}\right]$ Showing Switchable Dielectric, Magnetic, and Semiconducting Behaviour. Dalton Trans. 2019, 48, 16650-16660.

(40) Zhang, W.; Ye, H. Y.; Graf, R.; Spiess, H. W.; Yao, Y. F.; Zhu, R. Q.; Xiong, R. G. Tunable and Switchable Dielectric Constant in an Amphidynamic Crystal. J. Am. Chem. Soc. 2013, 135, 5230-5233.

(41) Qian, K.; Shao, F.; Yan, Z.; Pang, J.; Chen, X.; Yang, C. A Perovskite-Type Cage Compound as a Temperature-Triggered Dielectric Switchable Material. CrystEngComm 2016, 18, 7671-7674.

(42) Rok, M.; Prytys, J. K.; Kinzhybalo, V.; Bator, G. Flexible Crystals of Perovskite-like Coordination Polymers with a Tunable and Switchable Organic Guest: $\left(\mathrm{CH}_{3} \mathrm{NH}_{3}\right)_{2}\left[\mathrm{KFe}(\mathrm{CN})_{6}\right]$ and $\left(\mathrm{CH}_{3} \mathrm{NH}_{3}\right)_{2}\left[\mathrm{KCo}(\mathrm{CN})_{6}\right]$. Dalton Trans. 2017, 46, 2322-2331.

(43) Trzebiatowska, M.; Gagor, A.; Macalik, L.; Peksa, P.; Sieradzki, A. Phase Transition in the Extreme: A Cubic-to-Triclinic Symmetry Change in Dielectrically Switchable Cyanide Perovskites. Dalton Trans. 2019, 48, 15830-15840.

(44) Gong, Z. X.; Wang, Q. W.; Ma, J. J.; Jiang, J. Y.; E, D. Y.; Li, Z. Q.; Qi, F. W.; Liang, H. Reversible Structural Phase Transitions and Switchable Dielectric Behaviours in a Cyanometallate-Based Double Perovskite-Type Cage Compound: $\left[\mathrm{C}_{3} \mathrm{H}_{4} \mathrm{NS}\right]_{2}\left[\mathrm{KCo}(\mathrm{CN})_{6}\right]$. Mater. Chem. Front. 2020, 4, 918-923.

(45) Rok, M.; Moskwa, M.; Pawlukojć, A.; Janicki, R.; Zuba, I.; Zieliński, P.; Sobieszczyk, P.; Bator, G. Phase Transition Tuning by $\mathrm{Fe}(\mathrm{III}) / \mathrm{Co}$ (III) Substitution in Switchable Cyano-Bridged Perovskites: $\left(\mathrm{C}_{3} \mathrm{H}_{5} \mathrm{~N}_{2}\right)_{2}\left[\mathrm{KFe}_{\mathrm{x}} \mathrm{Co}_{1-\mathrm{x}}(\mathrm{CN})_{6}\right]$. Dalton Trans. 2020, 49, 55035512.

(46) Zhang, W.; Cai, Y.; Xiong, R.-G.; Yoshikawa, H.; Awaga, K. Exceptional Dielectric Phase Transitions in a Perovskite-Type Cage Compound. Angew. Chem., Int. Ed. 2010, 49, 6608-6610.

(47) Rok, M.; Bator, G.; Medycki, W.; Zamponi, M.; Balčiūnas, S.; Simenas, M.; Banys, J. Reorientational Dynamics of Organic Cations in Perovskite-like Coordination Polymers. Dalton Trans. 2018, 47, 17329-17341.

(48) Trzebiatowska, M.; Mączka, M.; Gagor, A.; Sieradzki, A. Pyrrolidinium-Based Cyanides: Unusual Architecture and Dielectric Switchability Triggered by Order-Disorder Process. Inorg. Chem. 2020, 59, 8855-8863.

(49) Szeremeta, A. Z.; Nowok, A.; Pawlus, S.; Fedoruk, K.; Trzebiatowska, M.; Mączka, M.; Symonowicz, J.; Paluch, M.; Sieradzki, A. Stable and Reversible Pressure-Controlled Dielectric Switching in Dicyanide Hybrid Perovskite. Appl. Mater. Today 2021, 22, 100957.

(50) Rok, M.; Bator, G.; Zarychta, B.; Dziuk, B.; Repeć, J.; Medycki, W.; Zamponi, M.; Usevičius, G.; Śimenas, M.; Banys, J. Isostructural Phase Transition, Quasielastic Neutron Scattering and Magnetic 
Resonance Studies of a Bistable Dielectric Ion-Pair Crystal $\left[\left(\mathrm{CH}_{3}\right)_{2} \mathrm{NH}_{2}\right]_{2} \mathrm{KCr}(\mathrm{CN})_{6}$. Dalton Trans. 2019, 48, 4190-4202.

(51) Zhang, H.-Y.; Lu, S.-Q.; Chen, X.; Xiong, R.-G.; Tang, Y.-Y. The First High-Temperature Multiaxial Ferroelectric Host-Guest Inclusion Compound. Chem. Commun. 2019, 55, 11571-11574.

(52) Gao, J.-X.; Hua, X.-N.; Chen, X.-G.; Liao, W.-Q. A High Temperature Optic-Electric Duple Switching Organic Ionic Compound: 1,4,7-Triazoniacyclononane Tetrafluoroborate Dichloride. J. Mat. Chem. C 2019, 7, 5348-5352.

(53) Liao, W.-Q.; Gao, J.-X.; Hua, X.-N.; Chen, X.-G.; Lu, Y. Unusual Two-Step Sequential Reversible Phase Transitions With Coexisting Switchable Nonlinear Optical and Dielectric Behaviors in $\left[\left(\mathrm{CH}_{3}\right)_{3} \mathrm{NCH}_{2} \mathrm{Cl}\right]_{2}\left[\mathrm{ZnCl}_{4}\right]$. J. Mat. Chem. C 2017, 5, 11873-11878.

(54) Xu, L.; Gao, J.-X.; Chen, X.-G.; Hua, X.-N.; Liao, W.-Q. A Temperature-Triggered Triplex Bistable Switch in a Hybrid Multifunctional Material: $\left[\left(\mathrm{CH}_{2}\right)_{4} \mathrm{~N}\left(\mathrm{CH}_{2}\right)_{4}\right]_{2}\left[\mathrm{MnBr}_{4}\right]$. Dalton Trans. 2018, 47, 16995-17003.

(55) Wu, Z.; Liu, X.; Ji, C.; Li, L.; Wang, S.; Sun, Z.; Zhang, W.; Peng, Y.; Luo, J. Above-Room-Temperature Switching of Quadratic Nonlinear Optical Properties in a Bi-Halide Organic-Inorganic Hybrid. J. Mat. Chem. C 2018, 6, 9532-9536.

(56) Zhang, J.; Han, S.; Liu, X.; Wu, Z.; Ji, C.; Sun, Z.; Luo, J. A Lead-Free Perovskite-Like Hybrid With Above-Room-Temperature Switching of Quadratic Nonlinear Optical Properties. Chem. Commun. 2018, 54, 5614-5617.

(57) Liu, X.; Ji, C.; Wu, Z.; Li, L.; Han, S.; Wang, Y.; Sun, Z.; Luo, J. $\left[\mathrm{C}_{5} \mathrm{H}_{12} \mathrm{~N}\right] \mathrm{SnCl}_{3}$ : A Tin Halide Organic-Inorganic Hybrid as an Above-Room-Temperature Solid-State Nonlinear Optical Switch. Chem. - Eur. J. 2019, 25, 2610-2615.

(58) Sun, Z.; Chen, T.; Liu, X.; Hong, M.; Luo, J. Plastic Transition to Switch Nonlinear Optical Properties Showing the Record High Contrast in a Single-Component Molecular Crystal. J. Am. Chem. Soc. 2015, 137, 15660-15663.

(59) Peksa, P.; Zareba, J. K.; Ptak, M.; Maczka, M.; Gagor, A.; Pawlus, S.; Sieradzki, A. Revisiting a Perovskite-Like Copper-Formate Framework $\mathrm{NH}_{4}\left[\mathrm{Cu}(\mathrm{HCOO})_{3}\right]$ : Order-Disorder Transition Influenced by Jahn-Teller Distortion and Above Room-Temperature Switching of the Nonlinear Optical Response Between Two SHGactive States. J. Phys. Chem. C 2020, 124, 18714-18723.

(60) Sheldrick, G. M. A Short History of SHELX. Acta Crystallogr. A. 2008, 64, 112-122.

(61) Xu, W. J.; Chen, S. L.; Hu, Z. T.; Lin, R. B.; Su, Y. J.; Zhang, W. X.; Chen, X. M. The Cation-Dependent Structural Phase Transition and Dielectric Response in a Family of Cyano-Bridged Perovskite-like Coordination Polymers. Dalton Trans. 2016, 45, 4224-4229.

(62) Wojciechowska, M.; Gagor, A.; Piecha-Bisiorek, A.; Jakubas, R.; Cizman, A.; Zaręba, J. K.; Nyk, M.; Zieliński, P.; Medycki, W.; Bil, A. Ferroelectricity and Ferroelasticity in Organic Inorganic Hybrid (Pyrrolidinium) $)_{3}\left[\mathrm{Sb}_{2} \mathrm{Cl}_{9}\right]$. Chem. Mater. 2018, 30, 4597-4608.

(63) Xu, W. J.; Du, Z. Y.; Zhang, W. X.; Chen, X. M. Structural Phase Transitions in Perovskite Compounds Based on Diatomic or Multiatomic Bridges. CrystEngComm 2016, 18, 7915-7928.

(64) Kieslich, G.; Sun, S.; Cheetham, A. K. An Extended Tolerance Factor Approach for Organic-Inorganic Perovskites. Chem. Sci. 2015, 6, 3430-3433.

(65) Becker, M.; Klüner, T.; Wark, M. Formation of Hybrid $\mathrm{ABX}_{3}$ Perovskite Compounds for Solar Cell Application: First-Principles Calculations of Effective Ionic Radii and Determination of Tolerance Factors. Dalton Trans. 2017, 46, 3500-3509.

(66) Shannon, R. D. Revised Effective Ionic Radii and Systematic Studies of Interatomic Distances in Halides and Chalcogenides. Acta Crystallogr. A 1976, 32, 751-767.

(67) Kieslich, G.; Sun, S.; Cheetham, A. K. Solid-State Principles Applied to Organic-Inorganic Perovskites: New Tricks for an Old Dog. Chem. Sci. 2014, 5, 4712-4715.

(68) Shi, C.; Yu, C.-H.; Zhang, W. Predicting and Screening Dielectric Transitions in a Series of Hybrid Organic-Inorganic Double Perovskites via an Extended Tolerance Factor Approach. Angew. Chem., Int. Ed. 2016, 55, 5798-5802.
(69) Maczka, M.; Stefanska, D.; Ga̧gor, A.; Pikul, A. The CationDependent Structural, Magnetic and Optical Properties in a Family of Hypophosphite Hybrid Perovskites. Dalton Trans. 2022, 51, 352360.

(70) Jones, L. H. Vibrational Spectrum and Structure of Single Crystals of $\mathrm{K}_{3} \mathrm{Co}(\mathrm{CN})_{6}$. J. Phys. Chem. 1962, 36, 1209-1215.

(71) Barsan, M. M.; Butler, I. S.; Fitzpatrick, J.; Gilson, D. F. R. High-Pressure Studies of the Micro-Raman Spectra of Iron Cyanide Complexes: Prussian Blue $\left(\mathrm{Fe}_{4}\left[\mathrm{Fe}(\mathrm{CN})_{6}\right]_{3}\right)$, Potassium Ferricyanide $\left(\mathrm{K}_{3}\left[\mathrm{Fe}(\mathrm{CN})_{6}\right]\right)$, and Sodium Nitroprusside $\left(\mathrm{Na}_{2}\left[\mathrm{Fe}(\mathrm{CN})_{5}(\mathrm{NO})\right]\right.$. $\left.2 \mathrm{H}_{2} \mathrm{O}\right)$. J. Raman Spectrosc. 2011, 42, 1820-1824.

(72) Rok, M.; Ciżman, A.; Zarychta, B.; Zaręba, J. K.; Trzebiatowska, M.; Mączka, M.; Stroppa, A.; Yuan, S.; Phillips, A. E.; Bator, G. Cyano-Bridged Perovskite $\left[\left(\mathrm{CH}_{3}\right)_{3} \mathrm{NOH}\right]_{2}\left[\mathrm{KM}(\mathrm{CN})_{6}\right]$, [M: $\mathrm{Fe}(\mathrm{III})$, and $\mathrm{Co}(\mathrm{III})]$ for High-Temperature Multi-Axial Ferroelectric Applications with Enhanced Thermal and Nonlinear Optical Performance. J. Mater. Chem. C 2020, 8, 17491-17501.

(73) Zhang, X.; Shao, X.-D.; Li, S.-C.; Cai, Y.; Yao, Y.-F.; Xiong, R.G.; Zhang, W. Dynamics of a Caged Imidazolium Cation-toward Understanding the Order-Disorder Phase Transition and the Switchable Dielectric Constant. Chem. Commun. 2015, 51, 45684571.

(74) Zhang, S.-Y.; Shu, X.; Zeng, Y.; Liu, Q.-Y.; Du, Z.-Y.; He, C.-T.; Zhang, W.-X.; Chen, X.-M. Molecule-Based Nonlinear Optical Switch with Highly Tunable on-off Temperature Using a Dual Solid Solution Approach. Nat. Commun. 2020, 11, 2752.

(75) Zhu, M.; Abdollahramezani, S.; Hemmatyar, O.; Adibi, A. Tunable Third-Harmonic Generation Using Low-Loss Phase Change Chalcogenides. In Photonic and Phononic Properties of Engineered Nanostructures XI, Proceedings of the SPIE, online only, Mar 2021, Vol. 11694, p $116941 \mathrm{~V}$

(76) Cao, T.; Liu, K.; Tang, Y.; Deng, J.; Li, K.; Li, G. A High-Index $\mathrm{Ge}_{2} \mathrm{Sb}_{2} \mathrm{Te}_{5}$-Based Fabry-Perot Cavity and Its Application for ThirdHarmonic Generation. Laser Photon. Rev. 2019, 13, 1900063.

(77) Kirk, A. D.; Schlafer, H. L.; Ludi, A. The Effect of the Cation on the ${ }^{2} \mathrm{E}_{\mathrm{g}}\left[\mathrm{Cr}(\mathrm{CN})_{6}\right]^{3-}$ and ${ }^{3} \mathrm{~T}_{1 \mathrm{~g}}\left[\mathrm{Co}(\mathrm{CN})_{6}\right]^{3-}$ Emissions: A Study of $\mathrm{Ag}_{3}\left[\mathrm{Cr}_{\mathrm{x}} \mathrm{Co}_{1-\mathrm{x}}(\mathrm{CN})_{6}\right]$. Can. J. Chem. 1970, 48, 1065-1072.

(78) Ptak, M.; Stefańska, D.; Gagor, A.; Svane, K. L. Walsh, A.; Paraguassu, W. Heterometallic Perovskite-Type Metal-Organic Framework with an Ammonium Cation: Structure, Phonons, and Optical Response of $\left[\mathrm{NH}_{4}\right] \mathrm{Na}_{0.5} \mathrm{Cr}_{\mathrm{x}} \mathrm{Al}_{0.5-\mathrm{x}}(\mathrm{HCOO})_{3}(\mathrm{x}=0,0.025$ and 0.5). Phys. Chem. Chem. Phys. 2018, 20, 22284-22295.

(79) Ptak, M.; Dziuk, B.; Stefańska, D.; Hermanowicz, K. The Structural, Phonon and Optical Properties of $\left[\mathrm{CH}_{3} \mathrm{NH}_{3}\right] \mathrm{M}_{0} \cdot{ }_{5} \mathrm{Cr}_{\mathrm{x}}$ $\mathrm{Al}_{0.5-\mathrm{x}}(\mathrm{HCOO})_{3}(\mathrm{M}=\mathrm{Na}, \mathrm{K} ; \mathrm{x}=0,0.025,0.5)$ Metal-Organic Framework Perovskites for Luminescence Thermometry. Phys. Chem. Chem. Phys. 2019, 21, 7965-7972.

(80) Ptak, M.; Zarychta, B.; Stefańska, D.; Ciupa, A.; Paraguassu, W. Novel Bimetallic MOF Phosphors with an Imidazolium Cation: Structure, Phonons, High- Pressure Phase Transitions and Optical Response. Dalton Trans. 2019, 48, 242-252.

(81) Dereń, P. J.; Malinowski, M.; Stręk, W. Site Selection Spectroscopy of $\mathrm{Cr}^{3+}$ in $\mathrm{MgAl}_{2} \mathrm{O}_{4}$ Green Spinel. J. Lumin. 1996, 68, 91-103.

(82) Chorazy, S.; Rams, M.; Wang, J.; Sieklucka, B.; Ohkoshi, S. Octahedral $\mathrm{Yb}(\mathrm{III})$ Complexes Embedded in $\left[\mathrm{Co}^{\mathrm{III}}(\mathrm{CN})_{6}\right]$-Bridged Coordination Chains: Combining Sensitized Near-Infrared Fluorescence with Slow Magnetic Relaxation. Dalton Trans. 2017, 46, 13668-13672.

(83) Flint, C. D.; Greenough, P. Luminescence Spectrum of the $\mathrm{Cr}(\mathrm{CN})^{3-}{ }_{6}$ Ion. J. Chem. Soc., Faraday Trans. 2 1974, 70, 815-882.

(84) Strek, W.; Trabjerg, I. The Temperature Dependence of the ${ }^{2} \mathrm{E}_{\mathrm{g}} \rightarrow{ }^{4} \mathrm{~A}_{2 \mathrm{~g}}$ Phosphorescence of $\left[\mathrm{Cr}(\mathrm{CN})_{6}\right]^{3-}$ in a $\mathrm{KCl}$ Host. Physica 1986, 141, 323-328.

(85) Yin, M.; Yusov, A. B.; Fedosseev, A. M.; Krupa, J. C. Optical Evidence of $\mathrm{Cr}^{3+}$ Ion Pairs in $\left(\mathrm{NH}_{4}\right)_{3}\left[\mathrm{Cr}(\mathrm{OH})_{6} \mathrm{Mo}_{6} \mathrm{O}_{18}\right] \cdot \mathrm{nH}_{2} \mathrm{O}$. J. Alloy. Compds. 2004, 377, 43-46. 